\title{
Studies of adsorption equilibria and kinetics of o-, m-, p-nitro- and chlorophenols on microporous carbons from aqueous solutions
}

\author{
Anna Derylo-Marczewska • Katarzyna Miroslaw • \\ Adam W. Marczewski · Dariusz Sternik
}

Received: 25 April 2010 / Accepted: 15 June 2010 / Published online: 10 July 2010

(C) The Author(s) 2010. This article is published with open access at Springerlink.com

\begin{abstract}
The studies of adsorption of $\mathrm{o}-, \mathrm{m}-$, and $\mathrm{p}$ nitrophenols and chlorophenols from aqueous solutions on microporous activated carbon are presented. The adsorption isotherms were measured at different temperatures: 288, 298, 308 and $318 \mathrm{~K}$. The thermal analysis was applied in order to find the differences in solute interactions with adsorbent surface. The kinetic dependences were measured and the relations between position of adsorbate functional groups and adsorption rate were discussed. The adsorption data are analyzed in terms of the theory of physical adsorption on energetically non-homogeneous solids. The relations between the adsorbate structure and adsorption effectiveness, and the influence of temperature are discussed.
\end{abstract}

Keywords Adsorption from solutions · Adsorption equilibria and kinetics · Microporous carbon

\section{Introduction}

Adsorption is a very effective process for removal of organic pollutants from fluids (Radovic et al. 2001; MorenoCastilla 2004; Deryło-Marczewska and Jaroniec 1987). The studies concentrate on manufacturing new types of cheap and effective adsorbents, and on the analysis of the influence of adsorbate system properties on adsorption uptake. Carbonaceous materials belong to a group of adsorbents showing very good sorption properties, chemically inert, environment friendly and relatively cheap. The methods of

A. Derylo-Marczewska $(\bowtie) \cdot$ K. Miroslaw $\cdot$ A.W. Marczewski D. Sternik

Institute of Chemistry, M. Curie-Skłodowska University, 20-031

Lublin, Poland

e-mail: annad@hektor.umcs.lublin.pl modification and characterization of carbons in order to increase their effectiveness in adsorption processes are widely investigated. Processes of adsorption of various aromatic compounds from solutions were widely analyzed to find some correlations between the sorption uptake and the adsorbate and adsorbent properties (Radovic et al. 1997, 2001; Moreno-Castilla 2004; Leng and Pinto 1997; Li et al. 2002; László 2005; Haydar et al. 2003; Okolo et al. 2000; LilloRódenas et al. 2005; Hsieh and Teng 2000; Franz et al. 2000; Deryło-Marczewska and Marczewski 2000, 2002). The adsorption effectiveness should be regarded as the result of adsorbent, adsorbate, and solvent properties, and the conditions of conducting the adsorption process. The affinity of different substances towards solids depends on many factors: adsorbate molecular structure and size, type of functional groups, solubility, acidity, interactions (especially intramolecular or intermolecular hydrogen bonding), as well as on the properties of solvent and adsorbent surface and structure characteristics. Regarding the complexity of studied adsorption systems it is very difficult to estimate the shares of separate effects on adsorption equilibria.

In the case of organic solutes in aqueous solutions their hydrophobicity is the main driving force for adsorption on hydrophobic surfaces. However, regarding adsorption of derivatives with different aromatic ring substituents we should also take into account their diverse affinity to the carbon surface (Radovic et al. 1997, 2001; Moreno-Castilla 2004; Leng and Pinto 1997; Li et al. 2002; László 2005; Haydar et al. 2003; Franz et al. 2000; Deryło-Marczewska and Marczewski 2000, 2002; Moreno-Castilla et al. 1995a; Deryło-Marczewska et al. 2006). The substituents of the aromatic solute ring influence the adsorption mechanism similarly as the surface groups of carbonaceous materials, affecting the dispersion interactions between the solute aromatic ring and the carbon graphene layers. Analysis of ad- 
sorption isotherms from aqueous solutions on the activated carbons for several bi-functional benzene derivatives with varying type and position of functional groups were presented in the papers (Deryło-Marczewska and Marczewski 2000, 2002). The values of adsorption equilibrium constants were correlated with solute solubility and acidity. The values of heterogeneity parameters reflecting the energetic non-homogeneity of adsorption system were analyzed by regarding the position of adsorbate functional groups. The relations between the adsorbate properties and adsorption parameters were found.

In the present paper, the investigations of equilibria and kinetics of adsorption of o-, m-, p-nitro- and chlorophenols from aqueous solutions on microporous activated carbon are presented and discussed. The experimental isotherms were measured at different temperatures: 288, 298, 308 and $318 \mathrm{~K}$, over a wide range of solute concentrations at low $\mathrm{pH}$ value $(\mathrm{pH}=2.2)$ where the adsorbate molecules are present in aqueous solution only in the nonionic forms. The profiles of adsorbate concentration change in time were obtained from the UV-Vis spectra measured for the cyclically collected samples of adsorbate solution. The kinetic dependences were analyzed in terms of different theoretical models. The relations between the adsorbate properties and structure- position of adsorbate functional groups-, and adsorption rate and effectiveness are discussed. The thermal analysis was applied in order to investigate the solute interactions with carbon surface.

\section{Experimental and calculation procedures}

\subsection{Carbon characterization}

The activated carbon RIAA (Norit n.v., Amersfoort, Netherlands) was chosen for the adsorption experiment. The structural characteristics of the studied carbon were determined from the nitrogen adsorption/desorption isotherm at $77 \mathrm{~K}$ measured volumetrically using Autosorb-1 analyzer (Quantachrome Instruments, USA).

The specific surface area, $S_{\mathrm{BET}}$, and the total pore volume, $V_{t}$, were obtained from the linear BET plot of adsorption data, and from the adsorption value at the rela- tive pressure $p / p_{0} \sim 0.98$, respectively (Gregg and Sing 1982). The values of the external (macropore) surface area, $S_{\text {ext }}$, and the primary mesopore volume, $V_{\text {mic }}$, were calculated from the $\alpha_{s}$ plot method by using the nongraphitized carbon black Cabot BP280 as a reference non-porous adsorbent (Kruk et al. 1997). The pore size distributions (PSD) were calculated by using the AS1 software (Quantachrome Instruments) following the NLDFT and HorvathKawazoe procedures for slit pores (Ravikovitch et al. 2000; Horvath and Kawazoe 1983). The pore diameters were estimated from the PSD maxima (mode, $D_{\text {mo }}$ ) and PSD average $\left(D_{\text {avg }}\right)$. The values of the structural parameters obtained for the activated carbon RIAA are presented in Table 1, however, in Fig. 1 the $\alpha_{s}$-plot and pore size distributions are presented.

2.2 Measurements and analysis of adsorption isotherms from solutions

The adsorbates 2-, 3-, 4-nitrophenol, and 2-, 3-, 4-chlorophenol, of analytical reagent grade were purchased from Sigma-Aldrich. The physicochemical properties of the used organics are listed in Table 2. The experimental isotherms for all solutes adsorption from dilute aqueous solutions on the carbon RIAA were measured at constant $\mathrm{pH}(\mathrm{pH}=2.2)$ and at different temperatures: $288,298,308$ and $318 \mathrm{~K}$ by using a static method. The $\mathrm{pH}$ was established by adding $\mathrm{HCl}$ solution. The adsorption experiment was prepared as follows: the known amount of carbon was first contacted with $5 \mathrm{~cm}^{3}$ of water and degassed under vacuum in Erlenmeyer flasks, the adsorbate solution of known concentration was added, the vessels were thermostated at $20^{\circ} \mathrm{C}$ and agitated until the equilibrium was attained. Finally, the equilibrium solute concentrations were measured by using the UVVIS spectrophotometer Cary 100 (Varian Inc., Australia). The adsorbed amount of organic compound was calculated from the material balance.

$a_{\mathrm{eq}}=\frac{\left(c_{0}-c_{\mathrm{eq}}\right) \cdot V}{w}$

where, $a_{\mathrm{eq}}$ is the equilibrium adsorbed amount, $c_{0}$ is the initial adsorbate concentration, $c_{\mathrm{eq}}$ is the equilibrium adsorbate

Table 1 Parameters characterizing the structural properties of the carbon RIAA

\begin{tabular}{llllllll}
\hline $\begin{array}{l}S_{\text {BET }} \\
{\left[\mathrm{m}^{2} \mathrm{~g}^{-1}\right]}\end{array}$ & $\begin{array}{l}S_{\text {ext }} \\
{\left[\mathrm{m}^{2} \mathrm{~g}^{-1}\right]}\end{array}$ & $\begin{array}{l}V_{t} \\
{\left[\mathrm{~cm}^{3} \mathrm{~g}^{-1}\right]}\end{array}$ & $\begin{array}{l}V_{\text {mic }} \\
{\left[\mathrm{cm}^{3} \mathrm{~g}^{-1}\right]}\end{array}$ & $\begin{array}{l}D_{h} \\
{[\mathrm{~nm}]}\end{array}$ & $\begin{array}{l}\text { Pore (slit) width } \\
\text { by NLDFT [nm }]\end{array}$ & $\begin{array}{l}\text { Pore (slit) width } \\
\text { by HK [nm }]\end{array}$ \\
\hline 1390 & 48 & 0.67 & 0.61 & 1.93 & 0.52 & 1.59 & 0.54 \\
\hline mo
\end{tabular}

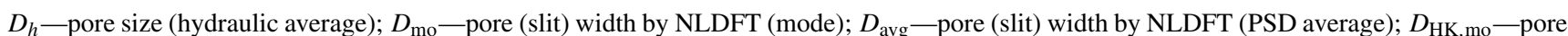
(slit) width by HK (mode); $D_{\mathrm{HK}, \text { avg }}$-pore (slit) width by HK (PSD average) 
Fig. 1 Adsorption isotherm (black triangles, thin line), and $\alpha_{s}$ plot (white diamonds, thick line) for nitrogen adsorption on the activated carbon RIAA.

Insert: pore size distributions (PSD) determined by NLDFT and Horvath-Kawazoe procedures

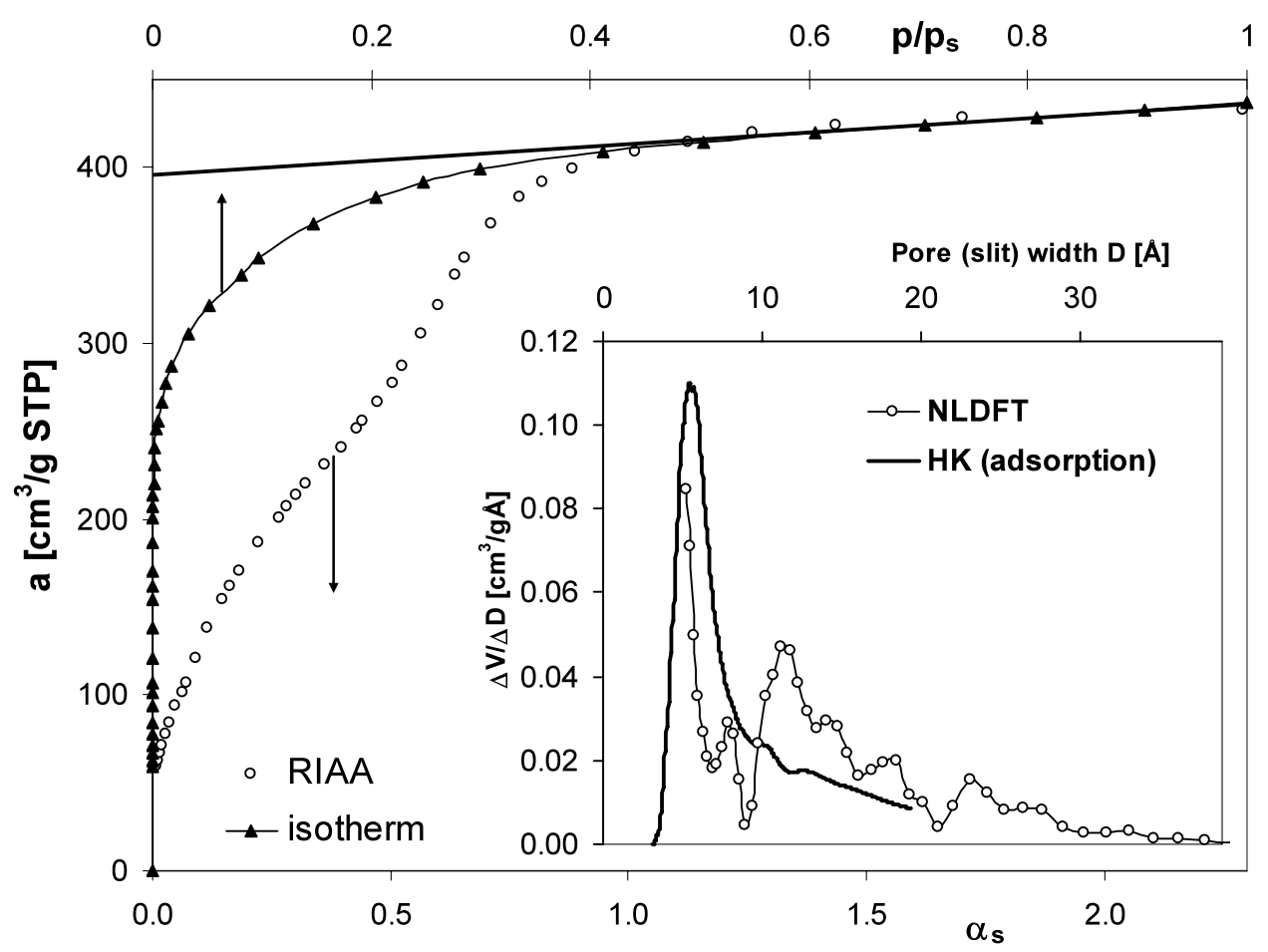

Table 2 Physicochemical properties of the studied adsorbates

\begin{tabular}{|c|c|c|c|c|c|c|}
\hline Compound & Code & $\begin{array}{l}M \\
{[\mathrm{~g} / \mathrm{mol}]}\end{array}$ & $\begin{array}{l}m . p . \\
{\left[{ }^{\circ} \mathrm{C}\right]}\end{array}$ & $\begin{array}{l}\text { b.p. } \\
{\left[{ }^{\circ} \mathrm{C}\right]}\end{array}$ & $\begin{array}{l}c_{s} \\
{[\mathrm{mmol} / \mathrm{g}]}\end{array}$ & $p K_{a}$ \\
\hline 2-Nitrophenol & $2 \mathrm{NPh}$ & 139.11 & 45 & 217 & 14.6 & 7.23 \\
\hline 3-Nitrophenol & $3 \mathrm{NPh}$ & 139.11 & 97 & 194 & 78 & 8.4 \\
\hline 4-Nitrophenol & $4 \mathrm{NPh}$ & 139.11 & 114 & subl. & 85 & 7.15 \\
\hline 2-Chlorophenol & $2 \mathrm{CPh}$ & 128.56 & 7 & 175 & 222 & 8.48 \\
\hline 3-Chlorophenol & $3 \mathrm{CPh}$ & 128.56 & 33 & 214 & 202 & 9.02 \\
\hline 4-Chlorophenol & $4 \mathrm{CPh}$ & 128.56 & 43 & 217 & 210 & 9.38 \\
\hline
\end{tabular}

m.p.-melting point temperature; b.p.-—boiling point temperature

concentration, $V$ is the solution volume, and $w$ is the adsorbent mass.

The experimental adsorption data were analyzed by the well-known Langmuir-Freundlich (LF) isotherm equation, taking into account the energetic heterogeneity of solids (Jaroniec and Madey 1988):

$\theta=\frac{\left(K c_{\mathrm{eq}}\right)^{m}}{1+\left(K c_{\mathrm{eq}}\right)^{m}}$

In the above, $\theta=a_{\mathrm{eq}} / a_{m}$ is the relative adsorption of organic solute over the whole surface phase, where $a_{m}$ is the adsorption capacity, the heterogeneity parameter $m$ characterizes the shape (width) of adsorption energy distribution function, and the equilibrium constant, $K$, describes the position of distribution function on energy axis.

\subsection{Kinetic measurements and analysis}

Kinetic measurements were conducted by applying the UVVis spectrophotometer Cary 100 (Varian Inc., Australia) with a flow cell to measure a solute concentration. The aqueous solutions of organic solutes of established initial concentration were contacted with a known amount of carbon in a specially constructed vessel; the solution was stirred during the experiment by applying a magnetic stirrer (Brandt et al. 2007; Marczewski 2007). At definite time intervals the solution samples were collected to the flow cell, the UV-Vis spectra were recorded and collected solution was returned to the vessel. The recorded absorbance spectra were analyzed for each kinetic point. The concentration vs. time and the adsorption vs. time profiles were calculated from the obtained spectra. 
Many kinetic equilibria may be described by using a general $n$th order equation, NOE (Cheung et al. 2001):

$$
\begin{aligned}
& \frac{d c}{d t}=-k_{n c}\left(c-c_{\mathrm{eq}}\right)^{n} \\
& \frac{d a}{d t}=-\frac{V}{w} \frac{d c}{d t}=k_{n a}\left(a_{\mathrm{eq}}-a\right)^{n} \\
& k_{n a}=k_{n c}(w / V)^{n-1}
\end{aligned}
$$

where $c$ is the temporary concentration, $a$ is the temporary adsorption, $t$ is time, subscript "eq" corresponds to the equilibrium values, $n$ is equation order and $k_{n}$ is the rate coefficient.

Rate equations expressed through changes of adsorbed amount (3b) are commonly called pseudo $n$th order equations (PNOE), however, both forms are mathematically equivalent (Marczewski 2010). Practically, only the first and the second order equations are used $(n=1,2)$. The pseudo first order equation, PFOE, is known as the Lagergren equation (Lagergren 1898) and its linear integrated form $\ln \left(a_{\mathrm{eq}}-a\right)=\ln a_{\mathrm{eq}}-k_{1} t$ is often used for data presentation purposes. However, the systems where PFOE successfully fit data are scarce, because it describes adsorption kinetics on non-porous, energetically homogeneous solids when concentration is almost constant or when adsorption isotherm is linear (Henry range). Nevertheless, many kinetic processes (eg. for heterogeneous Płaziński et al. 2009; Rudziński and Płaziński 2007 and porous solids Weber and Morris 1963; Crank 1975) close to equilibrium follow this general equation as in such situation non-linear effects and higher order terms practically disappear.

The integrated form of pseudo second order equation (PSOE) seems to be the most successful when data analysis is concerned. It is most often used in a simple linear form (Ho and McKay 1998a, 1998b; Ho 2006a, 2006b):

$$
\frac{t}{a}=\frac{1}{k_{2} a_{\mathrm{eq}}^{2}}+\frac{t}{a_{\mathrm{eq}}}
$$

Large part of PSOE success seems to result from its linear form which does not require advanced optimization techniques. However, the data transformation required for using (4) tends to emphasize the near-equilibrium data range, thus estimates of equilibrium adsorption are usually good, whereas the description of the initial part of experiment may be not satisfactory (Marczewski 2007; Deryło-Marczewska et al. 2010). One should also be aware, that PSOE may describe well strongly heterogeneous and/or porous systems or energetically homogeneous in situation when the change of concentration during kinetics is very high (Marczewski 2010; Azizian 2004).
An alternative linear plot of PSOE (Ho 2006b) proved to be helpful in showing if the model itself is truly applicable (Marczewski 2010; Deryło-Marczewska et al. 2010):

$a=a_{\mathrm{eq}}-\frac{1}{k_{2 a} a_{\mathrm{eq}}} \frac{a}{t}$

This equation shows kinetic data in a compact form, is linear in adsorption scale and exposes all the discrepancies from the linear PSOE behavior, however, it should not be used for data fitting purposes as it is sensitive to data scatter (Marczewski 2010; Deryło-Marczewska et al. 2010)standard LSQ optimization should be used for fitting and comparing of all models.

Recently, Marczewski (2010) presented application of a simple analytical equation corresponding to the linear combination of 1 st and 2 nd order rate equations (mixed 1,2order rate equation, MOE). This equation may be regarded as modeless generalization of FOE/SOE equations, but may also be treated as a solution of the Langmuir rate equation (Liu and Shen 2008). Earlier, Azizian (2004) proved that the Langmuir rate equation explains both the 1st order and 2nd order equations as boundary cases of Langmuir kinetic model (activated rate theory, ART). The former corresponds to weak adsorption and low adsorption uptakes (small concentration change), whereas the latter describes situation where adsorption is strong and uptake is close to complete. However, the Langmuir rate equation corresponds to adsorption on homogeneous solid surface and as such should not be applied to adsorption on microporous carbons.

In a series of papers Marczewski et al. (Brandt et al. 2007; Marczewski 2007, 2008; Deryło-Marczewska et al. 2010) introduced and analyzed the multi-exponential equation (m-exp), which may be treated as an approximation of a series of parallel first order processes (also structural or energetic heterogeneity) or a series of follow-up processes (e.g. in pores with constrictions). It was successfully used for analysis of adsorption kinetic data obtained for various energetically heterogeneous and porous solids. The multiexponential equation may be also treated as a kind of generalization of Lagergren equation:

$$
\begin{aligned}
& c=c_{0}\left(\sum_{i=1}^{n} A_{i} \exp \left(-k_{i} t\right)+A_{0}\right) \\
& \quad \text { where } A_{0}=c_{\mathrm{eq}} / c_{0} \text { and } \sum_{i=1}^{n} A_{i}=1-A_{0} \\
& c=\left(c_{0}-c_{\mathrm{eq}}\right) \sum_{i=1}^{n} f_{i} \exp \left(-k_{i} t\right)+c_{\mathrm{eq}} \\
& \quad \text { where } f_{i}=A_{i} /\left(1-A_{0}\right) \text { and } \sum_{i=1}^{n} f_{i}=1
\end{aligned}
$$


$a=a_{\mathrm{eq}}-a_{\mathrm{eq}} \sum_{i=1}^{n} f_{i} \exp \left(-k_{i} t\right)$

In the above $n$ is number of exponential terms. Parameters $A_{i}(i=0,1,2, \ldots, n)$ are normalized to unity which corresponds to the total amount of solute in the system $\left(V c_{0}=V c+w a\right): A_{0}$ describes relative equilibrium concentration and other $A_{i}$ parameters describe fraction of the adsorbate in the system (i.e. solution + adsorbent) following kinetics with a particular kinetics coefficient $k_{i}$. On the other hand coefficients $f_{i}(i=1,2, \ldots, n)$ describe fractions of total adsorbed amount corresponding to the processes characterized by the rate coefficients $k_{i}$.

Equation m-exp (6) should be able to describe experimental systems, where the initial process with fast adsorption rate is followed by a series of slower and slower processes. Such behavior may be expected, e.g. for porous adsorbents with non-uniform pore structure or a complicated pore network. This $(2 n+1)$-parameter equation fits very well many experimental data sets that could not be described by the 1st, 2nd order or end MOE. However, the quality of fitting obtained for MOE may be usually compared to the m-exp with 2 exponential terms.

\subsection{Thermal analysis}

Thermogravimetric analysis was performed with a derivatograph Q-1500 D (MOM, Hungary), with simultaneous recording of TG, DTG and DTA curves in relation to temperature and time. The samples were heated at $10 \mathrm{~K} \mathrm{~min}^{-1}$ rate in the temperature range of 298-1273 K. Analyses were carried out on the carbon samples before and after adsorption of organics.

\section{Results and discussion}

To study the process of adsorption from aqueous solutions on microporous activated carbon RIAA, the equilibrium isotherms for 2-, 3-, 4-nitrophenol, and 2-, 3-, 4chlorophenol were measured at different temperatures. In Figs. 2 and 3 the adsorption isotherms for 2-, 3- and 4- nitroand chlorophenols are compared at 288, 298, 308 and $318 \mathrm{~K}$. In the case of nitrophenols a distinctly stronger adsorption of 2-nitrophenol is observed, however, for chlorophenols only slight differences may be found among adsorption isotherms. The adsorption uptake correlates well with adsorbate hydrophobicity expressed by its solubility in water. Generally, the effectiveness of organics adsorption on carbonaceous materials depends mainly on solubility of the compound-the less soluble the substance, the higher adsorption value. In the case of nitrophenols, 2-nitrophenol is characterized by the lowest $c_{s}$ value (due to its intramolecular hydrogen bonding it has the lowest solvation energy), thus, its stronger hydrophobic interactions with carbon surface result in higher affinity towards adsorbent. In the case of chlorophenols slight differences among their solubilities result in similar adsorption effectiveness. However, in the analysis of adsorption process apart from adsorbate hydrophobicity the properties of adsorbed substance (molecular size, tendency to dissociation, properties of functional groups), adsorbent (structure and surface characteristics) and the conditions of conducting the adsorption process (solution $\mathrm{pH}$, ionic strength, temperature), which affect its affinity towards adsorbent surface should be regarded (Radovic et al. 2001; Moreno-Castilla 2004). The studied adsorption systems are differentiated only by the nature and position of substituent groups influencing their solubility and adsorptivity.

In Figs. 4 and 5 the influence of temperature on adsorption isotherms of 2-, 3-, 4-nitrophenol and 2-, 3-, 4chlorophenol is presented. In the case of nitrophenols the decrease of adsorption with temperature increase is observed; this effect is stronger for 2-nitrophenol. The temperature effect is also presented in Fig. 4 as the dependence of $\log K$ vs. $(1 / T)$. Such a behavior indicating the exothermic character of adsorption process may be explained by solubility increase resulting in adsorption decrease, and by increase of oscillation energy of adsorbate molecules resulting in easier desorption from surface phase to bulk phase. In the case of chlorophenols adsorption changes slightly with increasing temperature, however, it is difficult to determine the exact trend. Similarly as for nitrophenols, the largest temperature effect is observed for 2-chlorophenol. Such a behavior of adsorption systems may be a result of superposition of various opposite effects: the changes of solubility, oscillation energy and mobility of solute molecules from the bulk solution towards the adsorbent surface, rate of intraparticle diffusion.

In Table 3 the values of LSQ-fitted parameters of Langmuir-Freundlich isotherm are compared for adsorption of all nitro- and chlorophenols. In the case of all adsorption systems the values of heterogeneity parameter $m$, are low indicating strong heterogeneity effects. For nitrophenols the values of adsorption equilibrium constant, $K$, decrease distinctly with temperature increase. However, in the case of chlorophenols the temperature effect is very weak. Moreover, higher values of adsorption equilibrium constants for nitrophenols confirm their higher adsorption affinity to carbon surface in comparison to chlorophenols. The calculated values of Gibbs free energy change $(\Delta G=-R T \ln K)$ indicate the spontaneous character of adsorption process.

The analysis of measured profiles concentration vs. time also indicates some differences in adsorption process for the derivatives differentiated by the position of substituent groups. The obtained kinetic dependences are shown in 

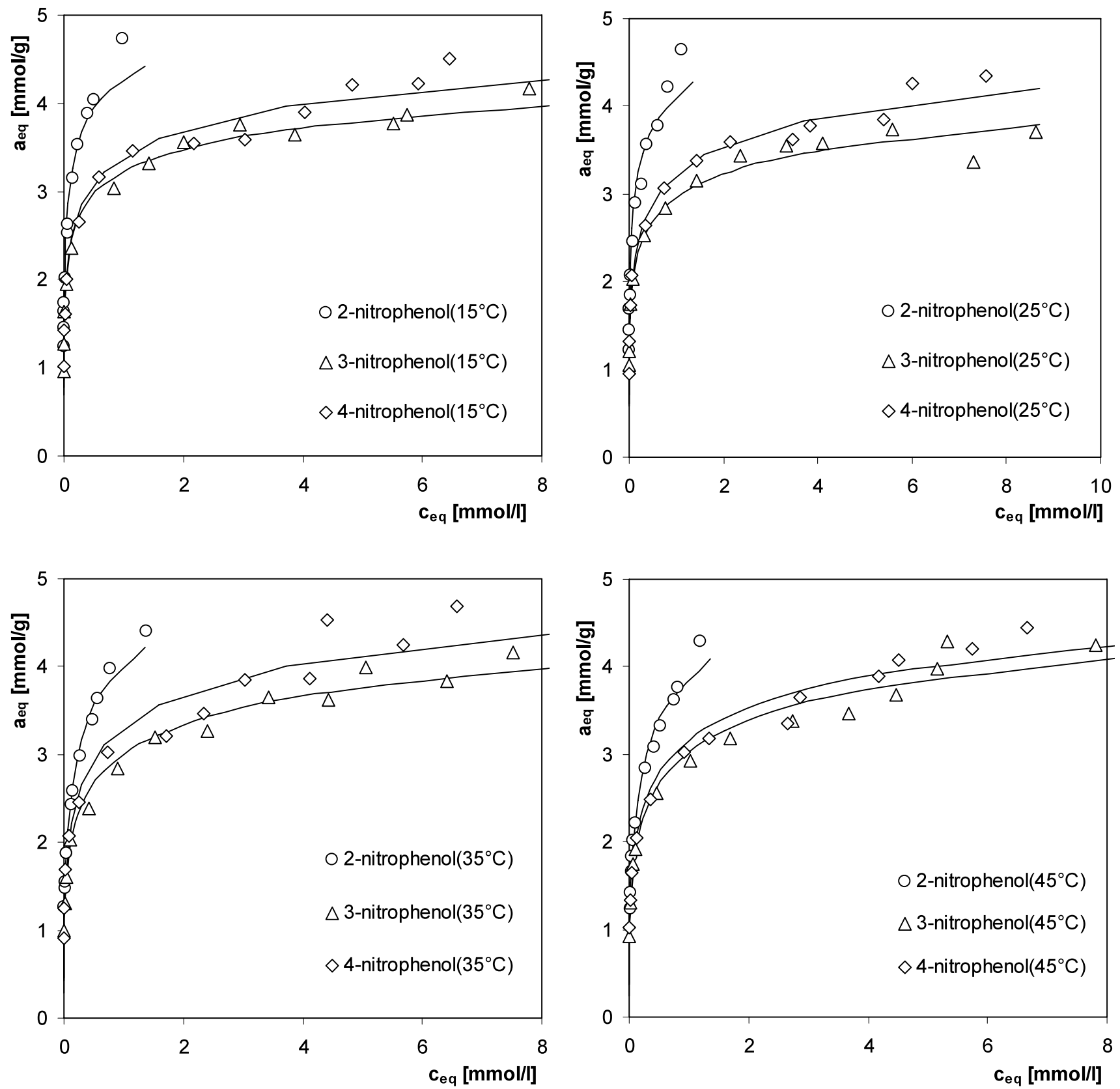

Fig. 2 Comparison of isotherms of 2-, 3-, and 4-nitrophenol adsorption from aqueous solutions on the activated carbon RIAA measured at different temperatures

Fig. 6 for nitrophenols (left) and chlorophenols (right) as relative concentration $c / c_{0}$ vs. time and as adsorbed amount $a$ vs. time plots. The lines correspond to the LSQ fit to the multi-exponential equation (m-exp) (6) with parameters shown in Table 4 . As we can see the quality of fit is very good (SD from $0.18-0.83 \%$ when compared to initial concentration). The m-exp parameters are shown as $A_{i}$ values as this kind of parameters shows also the residual concentration which is missing when we use $f_{i}=A_{i} / \sum_{j=1}^{n} A_{j}=$ $A_{i} /\left(1-A_{0}\right)$ parameters. In all cases the relative equilib- rium concentration was zero or close to zero, however, one should remember that it is fitted value for infinite time and thus is an extrapolated parameter. For 3- and 4-nitrophenol adsorption could be described satisfactorily by a single exponential term with a tiny second term for 4-nitrophenol. For 2-nitrophenol 3 exponential terms were required as in the case of all chlorophenols. However, analysis of tabular data is difficult, so all the parameters were plotted as the parameter spectrum $f_{i}=A_{i} /\left(1-A_{0}\right)$ vs. $k_{i}$ (Fig. 7) for nitrophenols (left) and chlorophenols (right). Now, the simi- 

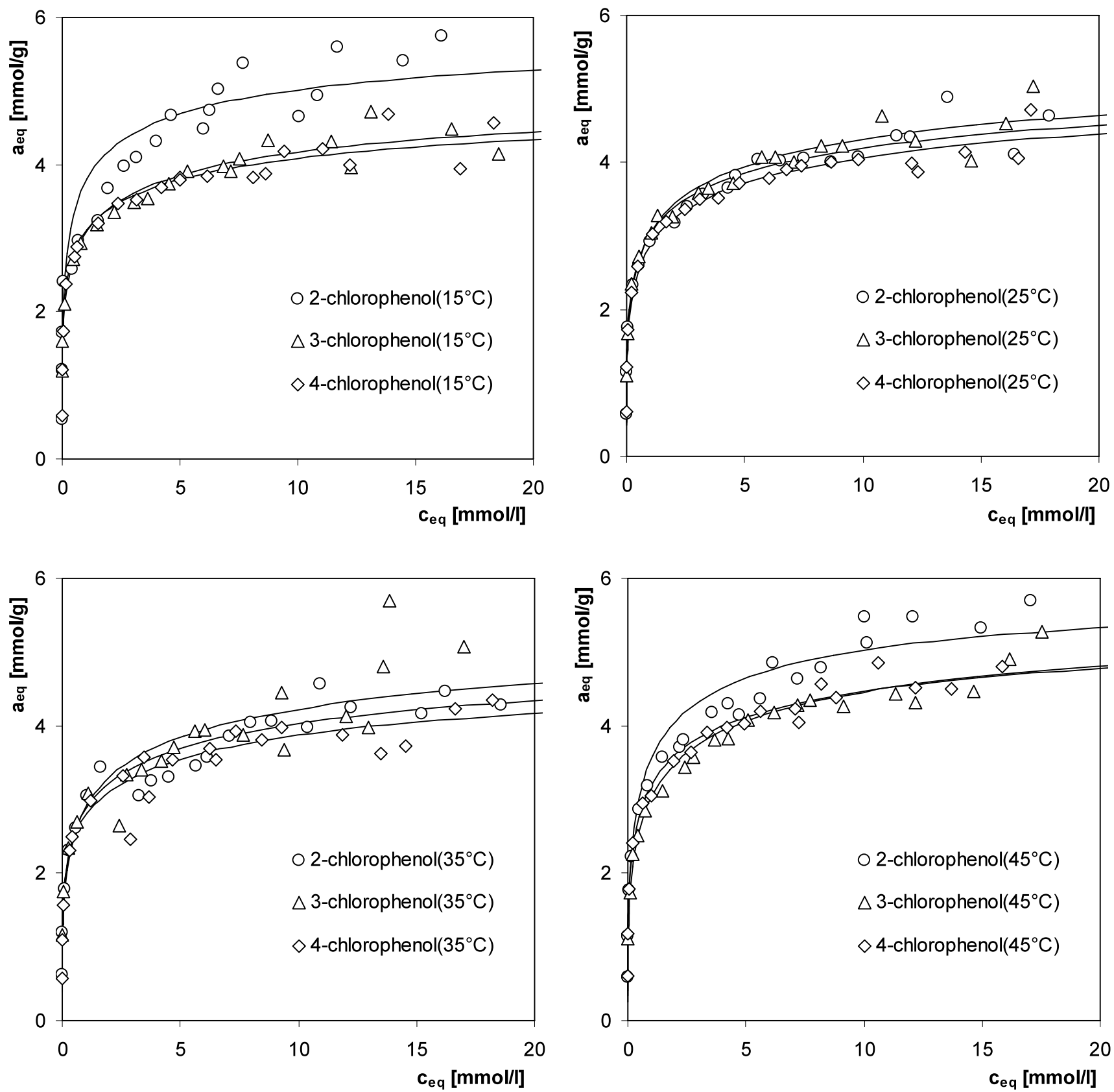

Fig. 3 Comparison of isotherms of 2-, 3-, and 4-chlorophenol adsorption from aqueous solutions on the activated carbon RIAA measured at different temperatures

larity of kinetic curves for 3- and 4-nitrophenols becomes obvious. For 2-nitrophenol the main part of the kinetics runs with practically the same rate coefficient $k \sim 0.002 / \mathrm{min}$ as for the other two nitrophenols, however, part of the solute is adsorbed with the rate approximately $5-10$ times faster and a small part with the rate approximately 3 times slower. For chlorophenols the kinetic curves and their parameter spectra are even more similar, though again the kinetics for 2-chlorophenol is a little different from the other two.
In order to show the varying kinetic rates not only by numerical fitting one may use the Lagergren plot $\ln \left(a_{\text {eq }}-\right.$ $a)=\ln a_{\mathrm{eq}}-k_{1} t$. Such dependences were plotted in Fig. 8 for 2-nitrophenol (left) and 2-chlorophenol (right). We can see that this data shows distinctly different linear sectionswe may see linear sections when the kinetic rate coefficients differ approximately at least 10 times in value (it depends also on the corresponding $f_{i}$ values).

This analysis relates well with the fitting of equilibrium isotherms, where strong heterogeneity effects were found. 

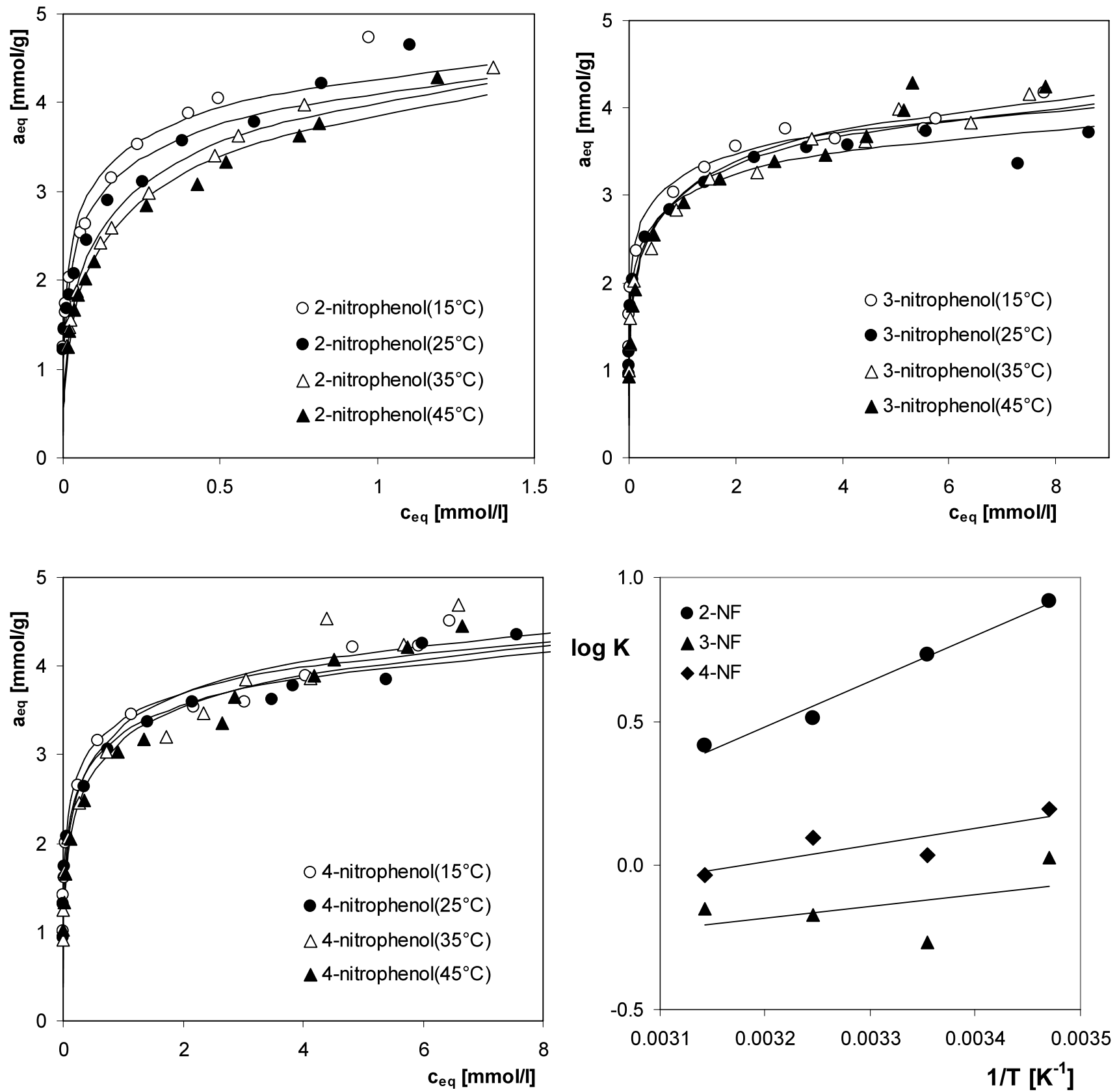

Fig. 4 Temperature effect on adsorption of 2-, 3-, and 4-nitrophenol from aqueous solutions on the activated carbon RIAA

According to many authors, e.g. Rudziński et al. (Płaziński et al. 2009; Rudziński and Płaziński 2007), the adsorption kinetics in heterogeneous systems may be well described by the second order equation SOE/PSOE. PSOE is used most often in its "standard" linear form $t / a$ vs. $t$ (4). This form is very attractive because of easy fitting not requiring complicated data transformations or optimization techniques. The results of fitting the PSOE to the nitrophenols' and chlorophenols' kinetic data are shown in Tables 5 and 6 and in graphic form in Fig. 9 for 2-nitrophenol (left) and 2-chlorophenol (right). The open circles represent the en- tire kinetic data, whereas, black circles cover only the nearequilibrium data (but half of experiment's time). As we can see the linearity is very good even for all data, though the lines fitted close to equilibrium deviate slightly from experimental points in the initial part of experiments. For comparison the alternative linear PSOE plot $a$ vs. $a / t$ (5) was also used in Fig. 9. The white triangles correspond to the entire data sets, whereas the black triangles correspond to the near-equilibrium data (the same range as for linear plot (4) — data represented by black circles). We can see that the deviation from linearity expected for PSOE is quite distinct 

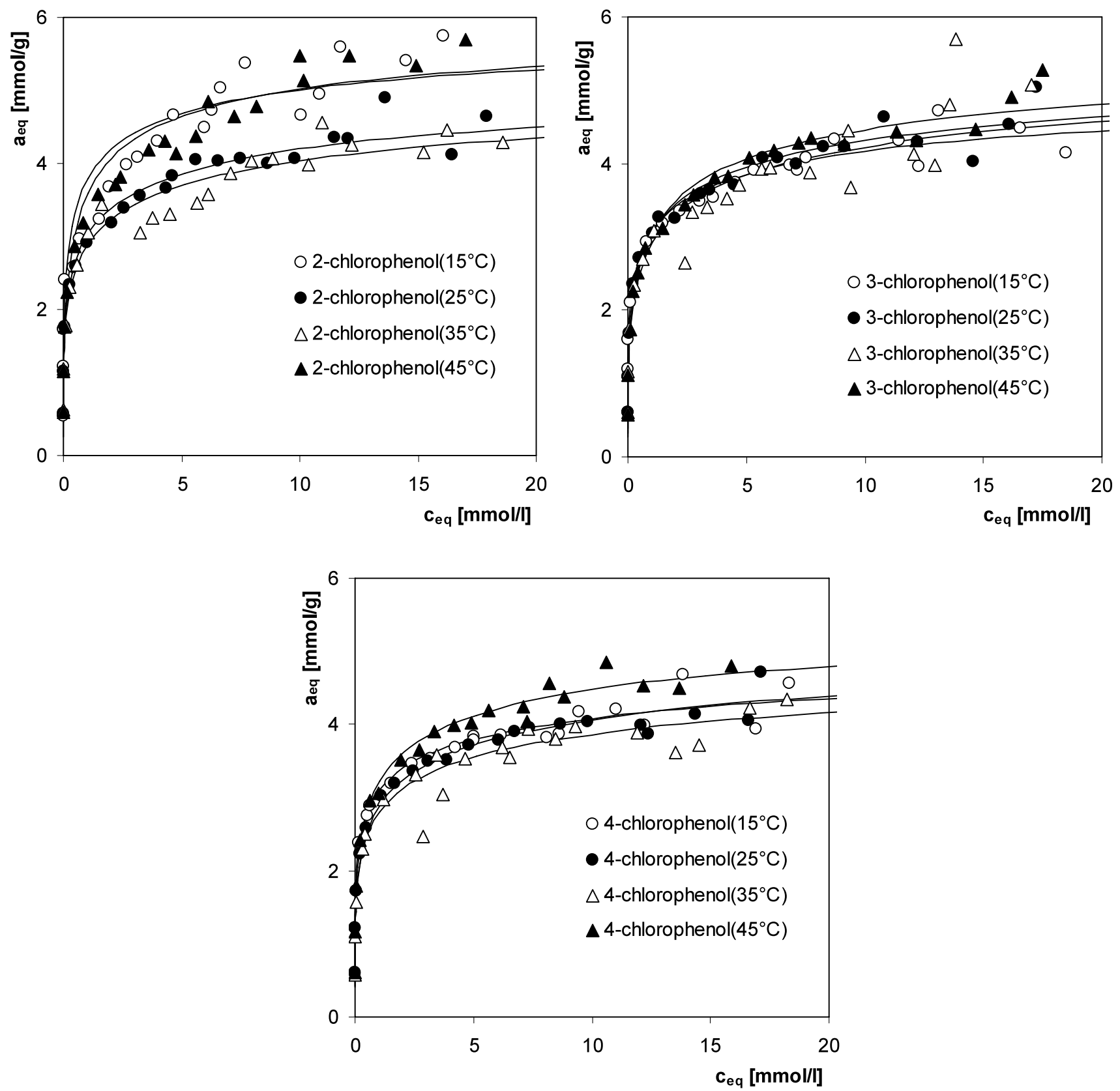

Fig. 5 Temperature effect on adsorption of 2-, 3-, and 4-chlorophenol from aqueous solutions on the activated carbon RIAA

and the lines fitted near equilibrium have slope quite different from that of the entire data. The parameters obtained by fitting PSOE to the various data ranges by using linear relationships (4) a (5) are presented in Tables 5 (nitrophenols) and 6 (chlorophenols). We can see that while the linear plot (4) produces reliable estimation of equilibrium adsorption values $a_{\text {eq }}$ (derived from the plot slope) the values of $k_{2}$ (derived from the abscissa intercept) often deviate strongly. In the case of the linear plot (5) the values of $a_{\text {eq }}$ also show certain variability and the same may be said about $k_{2}$. However, the initial ranges used for this plot were very narrow
(0-100 min), thus, in this case the parameter values are distinctly different than those obtained for the entire data or near-equilibrium subsets. It confirms, that the PSOE cannot describe the entire data properly, but also suggests strongly that energetic heterogeneity and porous structure is responsible for this behavior. However, we can see that the parameters obtained from near-equilibrium data by using both linear plots are very similar, though obviously cannot and should not be used to describe the entire kinetic experiments.

In order to compare quality of fitting for multi-exponential equation (6) and by using PSOE equation (4) the plot of 
Table 3 Parameters characterizing adsorption of the studied solutes from aqueous solutions on the carbon RIAA, determined from the LangmuirFreundlich equation (2) by using fitting procedure ( $K$ in $[\mathrm{L} / \mathrm{mmol}])$

\begin{tabular}{|c|c|c|c|c|c|c|c|c|}
\hline \multirow[t]{2}{*}{ Adsorbate } & \multicolumn{4}{|c|}{ Nitrophenols } & \multicolumn{4}{|c|}{ Chlorophenols } \\
\hline & $15^{\circ} \mathrm{C}$ & $25^{\circ} \mathrm{C}$ & $35^{\circ} \mathrm{C}$ & $45^{\circ} \mathrm{C}$ & $15^{\circ} \mathrm{C}$ & $25^{\circ} \mathrm{C}$ & $35^{\circ} \mathrm{C}$ & $45^{\circ} \mathrm{C}$ \\
\hline & \multicolumn{4}{|c|}{ 2-nitrophenol (2NPh) } & \multicolumn{4}{|c|}{ 2-chlorophenol (2CPh) } \\
\hline$m$ & 0.35 & 0.37 & 0.46 & 0.45 & 0.45 & 0.34 & 0.34 & 冫 \\
\hline $\log K$ & 0.86 & 0.69 & 0.53 & 0.39 & -0.04 & -0.18 & -0.31 & -0.43 \\
\hline \multirow[t]{2}{*}{$\Delta G[\mathrm{~kJ} / \mathrm{mol}]$} & -21.27 & -21.06 & -20.85 & -20.64 & -16.35 & -16.12 & -15.88 & -15.64 \\
\hline & \multicolumn{4}{|c|}{ 3-nitrophenol (3NPh) } & \multicolumn{4}{|c|}{ 3-chlorophenol (3CPh) } \\
\hline$m$ & 0.24 & 0.24 & 0.31 & 0.33 & 0.29 & 0.35 & 0.35 & 0.40 \\
\hline $\log K$ & -0.03 & -0.09 & -0.15 & -0.21 & -0.09 & -0.15 & -0.21 & -0.13 \\
\hline \multirow[t]{2}{*}{$\Delta G[\mathrm{~kJ} / \mathrm{mol}]$} & -16.4 & -16.6 & -16.79 & -16.98 & -16.07 & -16.26 & -16.46 & -17.48 \\
\hline & \multicolumn{4}{|c|}{ 4-nitrophenol (4NPh) } & \multicolumn{4}{|c|}{ 4-chlorophenol (4CPh) } \\
\hline$m$ & 0.28 & 0.29 & 0.34 & 0.34 & 0.29 & 0.31 & 0.31 & 0.45 \\
\hline $\log K$ & 0.14 & 0.07 & 0.01 & -0.05 & -0.13 & -0.27 & -0.4 & -0.53 \\
\hline$\Delta G[\mathrm{~kJ} / \mathrm{mol}]$ & -17.34 & -17.55 & -17.76 & -17.97 & -15.81 & -15.56 & -15.32 & -15.07 \\
\hline
\end{tabular}

Table 4 The parameters of multi-exponential kinetic equation (6) $\left(k_{i}\right.$ in $\left.\left[\mathrm{min}^{-1}\right]\right)$

\begin{tabular}{llllll}
\hline Adsorbate & $A_{1}\left(k_{1}\right)$ & $A_{2}\left(k_{2}\right)$ & $A_{3}\left(k_{3}\right)$ & $A_{0}$ & $\mathrm{SD}\left(c / c_{0}\right)$ \\
\hline $2 \mathrm{NPh}$ & $0.323(0.0078)$ & $0.578(0.0016)$ & $0.095(0.00056)$ & 0.0041 & 0 \\
$3 \mathrm{NPh}$ & $1 \quad(0.0017)$ & - & - & 0 & 0.0041 \\
$4 \mathrm{NPh}$ & $0.992(0.0021)$ & $0.008(0.00028)$ & - & $0.078(0.00036)$ & 0 \\
$2 \mathrm{CPh}$ & $0.347(0.008)$ & $0.575(0.0016)$ & $0.622(0.00128)$ & 0 & 0.003 \\
$3 \mathrm{CPh}$ & $0.054(0.021)$ & $0.324(0.0025)$ & $0.291(0.00054)$ & 0.021 \\
$4 \mathrm{CPh}$ & $0.032(0.018)$ & $0.657(0.0017)$ & & 0.0018 \\
\hline
\end{tabular}

$\mathrm{SD}^{*}=\frac{1}{c_{0}} \sqrt{\sum_{i=1}^{L}\left(c_{i}-c\left(t_{i}\right)\right)^{2} /(L-(2 n+1))}$ where $L$ is the number of experimental points

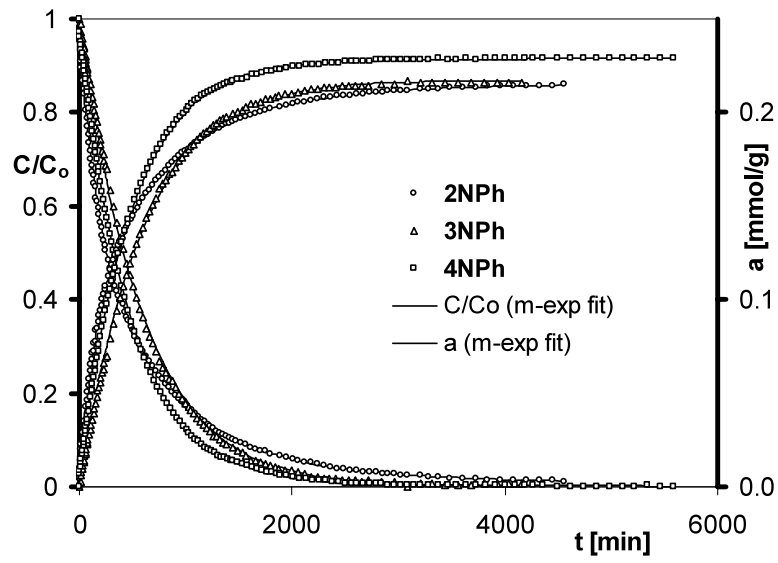

Fig. 6 Comparison of adsorption kinetics of 2-, 3- and 4-nitrophenol (left) and 2-, 3- and 4-chlorophenol (right) on activated carbon RIAA (points). Relative concentration (decreasing curves) and adsorbed val-

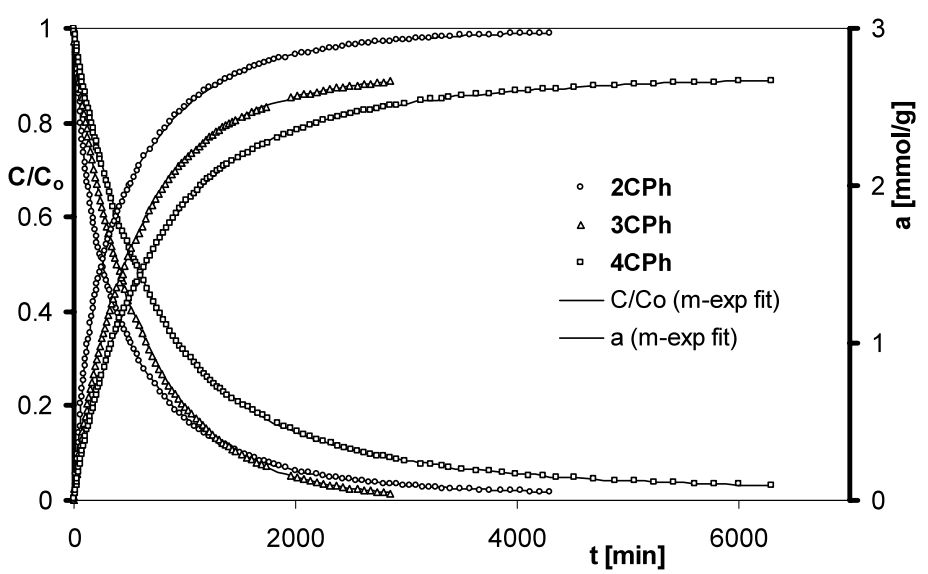

ues (increasing curves) are shown. Lines are calculated according to the multi-exponential equation (6) (parameters in Table 4) 

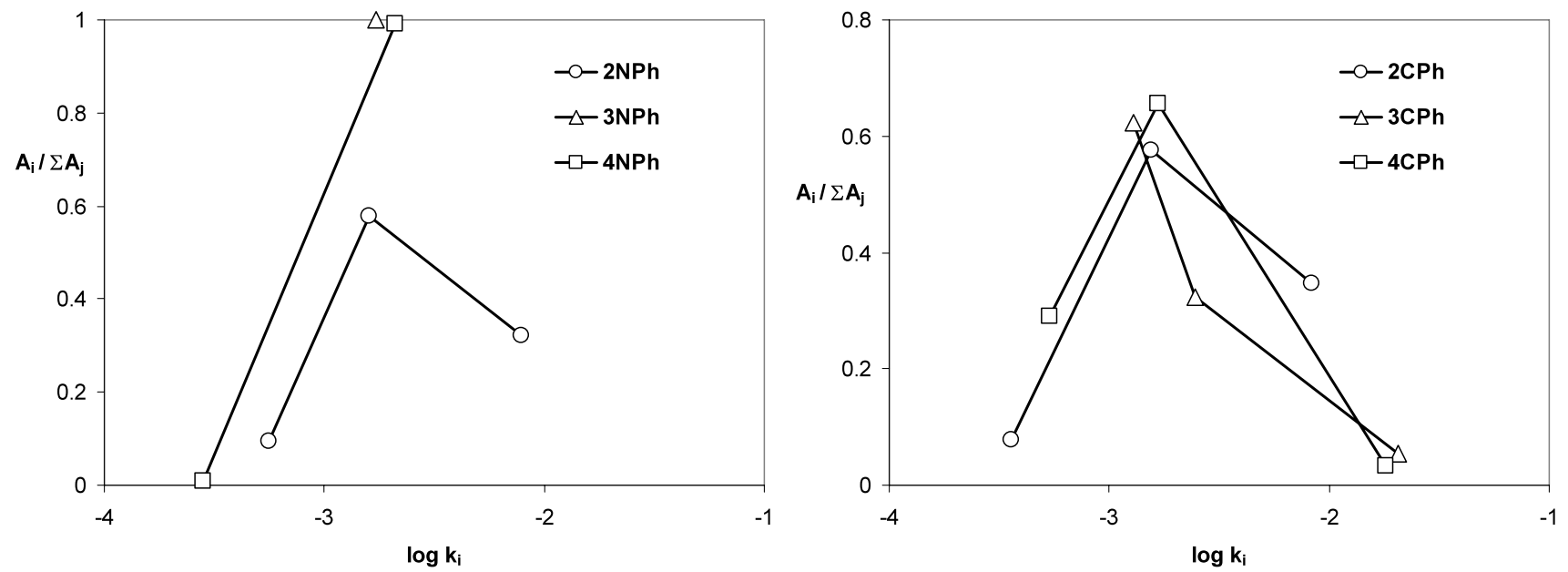

Fig. 7 Parameter spectra of multi-exponential equation (6) fitted to the nitrophenol (left) and chlorophenol (right) adsorption kinetics on RIAA carbons (see Table 4)
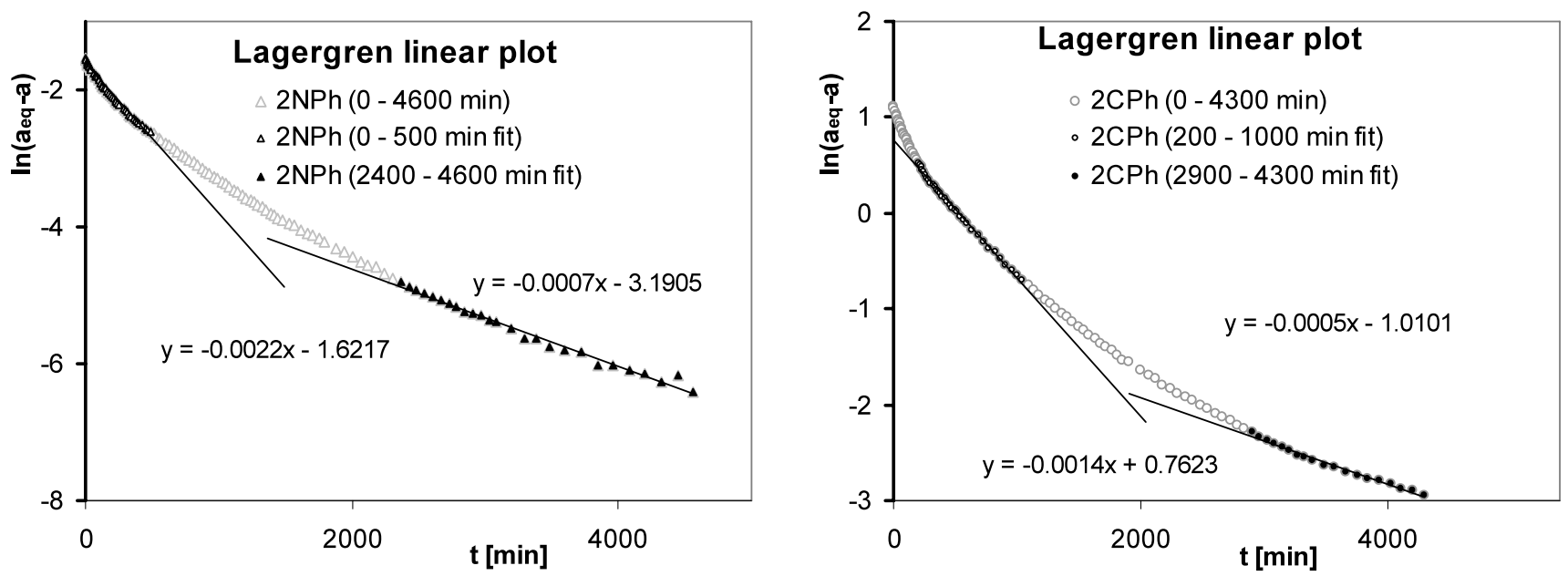

Fig. 8 Lagergren plots of adsorption kinetics of 2-nitrophenol (left) and 2-chlorophenol on RIAA carbon (see Fig. 6). The points and fitted lines show various linearity ranges of experimental data

optimized vs. experimental adsorption values is presented in Fig. 10 for 2-nitrophenol (left) and 2-chlorophenol (right). The thick gray lines correspond to the "perfect fit", the open circles are calculated according to m-exp equation (6) (see Table 4), whereas triangles correspond to PSOE with parameters calculated by fitting in the indicated time ranges (see Tables 5 and 6 ) by using standard plot (4). W may see that the fit by m-exp is almost perfect and the fit obtained using PSOE parameters fitted to the entire data is also quite good, though we may observe systematic deviations from the "perfect fit" line for 2-nitrophenol. As it might be expected, the highest deviations are obtained when we employ parameters obtained by fitting PSOE to the near-equilibrium data. However, the deviations displayed by PSOE fitting obtained for the other nitro- and chlorophenols (not shown) are generally greater.
Summing up, we may conclude, that the PSOE equation $(4,5)$ may be used for description of such kinetic data, but should be used mainly for the estimation of equilibrium adsorption value $a_{\text {eq }}$. Multi-exponential (m-exp) equation (6) proved to be able to describe such data very precisely and analysis of its parameter spectrum allows to compare and better understand corresponding kinetic processes.

In Figs. 11, 12, 13 and 14 the DTG and DTA curves measured for the pure carbon RIAA (a) and the carbon loaded with adsorbates (b, c, d) are presented. Analyzing these dependences in the range $20-950^{\circ} \mathrm{C}$ for pure carbon RIAA (a) we can find 3 main stages of thermooxidation (DeryłoMarczewska et al. 2010). The mass loss at about $83^{\circ} \mathrm{C}$ is related to endothermic process of desorption of physically adsorbed water. In the range $400-640^{\circ} \mathrm{C}$ the surface oxi- 
Table 5 Parameters of pseudo 2nd order kinetic equation fitted in various linear coordinates and time ranges (nitrophenols) fitted by using the standard and alternative linear plots $(4,5)\left(a_{\mathrm{eq}}[\mathrm{mmol} / \mathrm{g}], t[\mathrm{~min}], t / a[\mathrm{~min} \mathrm{~g} / \mathrm{mmol}], k_{2}\left[\mathrm{~min}^{-1}\right]\right)$

\begin{tabular}{|c|c|c|c|c|c|c|c|c|}
\hline Adsorbate & slope & $a b s c$ & $R^{2}$ & $t_{\min }-t_{\max }[\min ]$ & $a_{\mathrm{eq}}$ & $k_{2}$ & $\operatorname{SD}\left(c / c_{0}\right)$ & $\operatorname{SD}\left(a / a_{\mathrm{eq}}\right)$ \\
\hline \multicolumn{9}{|c|}{2 nd order linear fit: $t / a \sim t$} \\
\hline \multirow[t]{3}{*}{$2 \mathrm{NPh}$} & 4.36 & 1170 & 0.999 & $0-4600$ & 0.230 & 0.0163 & $1.6 \%$ & $1.3 \%$ \\
\hline & 4.66 & 1100 & 0.987 & $0-900$ & 0.215 & 0.0197 & $3.7 \%$ & $3.9 \%$ \\
\hline & 4.50 & 674 & 1.000 & $2400-4600$ & 0.222 & 0.0301 & $8.9 \%$ & $8.5 \%$ \\
\hline \multirow[t]{3}{*}{$3 \mathrm{NPh}$} & 3.78 & 2330 & 0.977 & $0-4200$ & 0.264 & 0.00614 & $4.5 \%$ & $3.7 \%$ \\
\hline & 2.59 & 2880 & 0.637 & $0-1100$ & 0.386 & 0.00233 & $15 \%$ & $8.5 \%$ \\
\hline & 4.58 & 168 & 1.000 & $2700-4200$ & 0.218 & 0.125 & $33 \%$ & $33 \%$ \\
\hline \multirow[t]{3}{*}{$4 \mathrm{NPh}$} & 4.02 & 1260 & 0.997 & $0-5600$ & 0.249 & 0.0128 & $4.3 \%$ & $3.9 \%$ \\
\hline & 3.36 & 1670 & 0.944 & $0-1000$ & 0.298 & 0.00676 & $8.7 \%$ & $6.4 \%$ \\
\hline & 4.34 & 122 & 1.000 & $2500-5600$ & 0.230 & 0.155 & $30 \%$ & $28 \%$ \\
\hline \multicolumn{9}{|c|}{ 2nd order linear fit: $a \sim a / t$} \\
\hline \multirow[t]{3}{*}{$2 \mathrm{NPh}$} & -175 & 0.206 & 0.800 & $0-4600$ & 0.206 & 0.0279 & $5.7 \%$ & $6.2 \%$ \\
\hline & -24.0 & 0.051 & 0.715 & $0-100$ & 0.051 & 0.821 & $55 \%$ & $236 \%$ \\
\hline & -156 & 0.222 & 0.983 & $2400-4600$ & 0.222 & 0.0289 & $8.4 \%$ & $8.0 \%$ \\
\hline \multirow[t]{3}{*}{$3 \mathrm{NPh}$} & -354 & 0.203 & 0.317 & $0-4200$ & 0.203 & 0.0139 & $12 \%$ & $13 \%$ \\
\hline & 12.3 & 0.006 & 0.372 & $0-100$ & 0.006 & -13.2 & $138 \%$ & $4870 \%$ \\
\hline & -44.6 & 0.219 & 0.435 & $2700-4200$ & 0.219 & 0.103 & $31 \%$ & $31 \%$ \\
\hline \multirow[t]{3}{*}{$4 \mathrm{NPh}$} & -153 & 0.207 & 0.461 & $0-5600$ & 0.207 & 0.0315 & $12 \%$ & $14 \%$ \\
\hline & -5.50 & 0.022 & 0.443 & $0-100$ & 0.022 & 8.11 & $71 \%$ & $737 \%$ \\
\hline & -31.7 & 0.230 & 0.898 & $2500-5600$ & 0.230 & 0.137 & $29 \%$ & $27 \%$ \\
\hline
\end{tabular}

Table 6 Parameters of pseudo 2nd order kinetic equation fitted in various linear coordinates and time ranges (chlorophenols) fitted by using the standard and alternative linear plots $(4,5)$ (units as in Table 5)

\begin{tabular}{|c|c|c|c|c|c|c|c|c|}
\hline Adsorbate & slope & $a b s c$ & $R^{2}$ & $t_{\min }-t_{\max }[\min ]$ & $a_{\mathrm{eq}}$ & $k_{2}$ & $\mathrm{SD}\left(c / c_{0}\right)$ & $\mathrm{SD}\left(a / a_{\mathrm{eq}}\right)$ \\
\hline \multicolumn{9}{|c|}{ 2nd order linear fit: $t / a \sim t$} \\
\hline \multirow[t]{3}{*}{$2 \mathrm{CPh}$} & 0.312 & 88.8 & 1.000 & $0-4300$ & 3.20 & 0.0011 & $0.69 \%$ & $0.65 \%$ \\
\hline & 0.312 & 90.7 & 0.999 & $0-1000$ & 3.21 & 0.00107 & $0.73 \%$ & $0.68 \%$ \\
\hline & 0.317 & 74.7 & 1.000 & $1000-4300$ & 3.15 & 0.00135 & $2.7 \%$ & $2.6 \%$ \\
\hline \multirow[t]{3}{*}{$3 \mathrm{CPh}$} & 0.317 & 151 & 0.998 & $0-2900$ & 3.16 & 0.00066 & $1.4 \%$ & $1.2 \%$ \\
\hline & 0.318 & 153 & 0.982 & $0-1100$ & 3.15 & 0.00066 & $1.4 \%$ & $1.2 \%$ \\
\hline & 0.336 & 109 & 1.000 & $1500-2900$ & 2.97 & 0.00104 & $5.8 \%$ & $5.3 \%$ \\
\hline \multirow[t]{3}{*}{$4 \mathrm{CPh}$} & 0.331 & 215 & 0.994 & $0-6300$ & 3.03 & 0.00051 & $1.7 \%$ & $1.6 \%$ \\
\hline & 0.296 & 239 & 0.693 & $0-900$ & 3.37 & 0.00037 & $3.6 \%$ & $3.2 \%$ \\
\hline & 0.353 & 128 & 1.000 & $2500-6300$ & 2.83 & 0.00098 & $8.1 \%$ & $7.5 \%$ \\
\hline \multicolumn{9}{|c|}{ 2nd order linear fit: $a \sim a / t$} \\
\hline \multirow[t]{3}{*}{$2 \mathrm{CPh}$} & -294 & 3.23 & 0.995 & $0-4300$ & 3.23 & 0.00106 & $0.68 \%$ & $0.64 \%$ \\
\hline & -492 & 5.03 & 0.507 & $0-100$ & 5.03 & 0.00040 & $31 \%$ & $19 \%$ \\
\hline & -172 & 3.10 & 0.987 & $2500-4300$ & 3.10 & 0.00188 & $6.8 \%$ & $6.7 \%$ \\
\hline \multirow[t]{3}{*}{$3 \mathrm{CPh}$} & -400 & 2.94 & 0.912 & $0-2900$ & 2.94 & 0.00085 & $3.2 \%$ & $2.9 \%$ \\
\hline & -74.7 & 0.76 & 0.755 & $0-100$ & 0.76 & 0.0176 & $47 \%$ & $168 \%$ \\
\hline & -333 & 2.98 & 0.990 & $1500-2900$ & 2.98 & 0.00101 & $5.5 \%$ & $4.9 \%$ \\
\hline \multirow[t]{3}{*}{$4 \mathrm{CPh}$} & -279 & 2.18 & 0.280 & $0-6300$ & 2.18 & 0.00164 & $13 \%$ & $16 \%$ \\
\hline & 11.8 & 0.09 & 0.343 & $0-100$ & 0.09 & -0.932 & $65 \%$ & $1970 \%$ \\
\hline & -377 & 2.84 & 0.991 & $2500-6300$ & 2.84 & 0.00094 & $7.5 \%$ & $6.9 \%$ \\
\hline
\end{tabular}




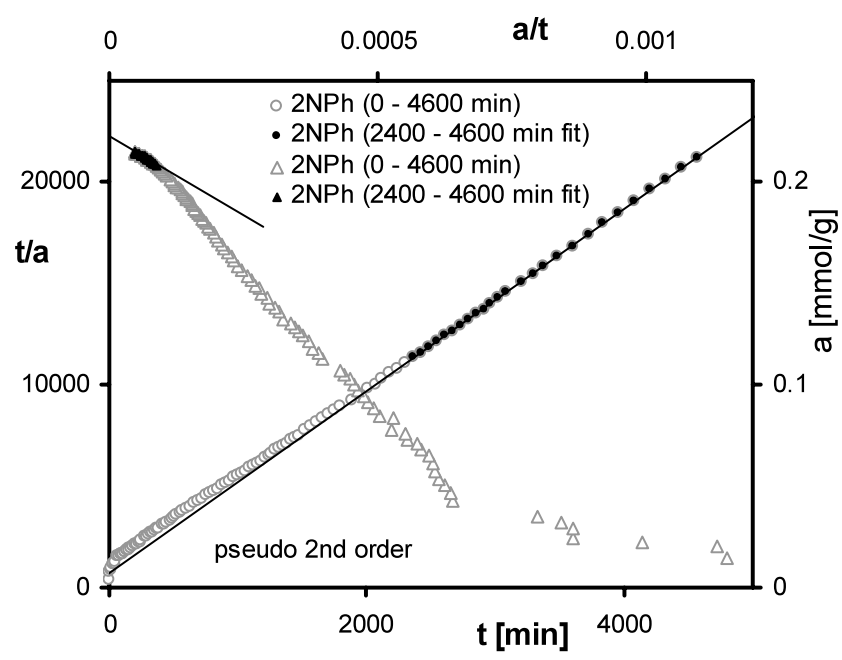

Fig. 9 PSOE linear plots of adsorption kinetics of 2-nitrophenol (left) and 2-chlorophenol (right) on RIAA carbon. Standard $t / a$ vs. time plot is compared with the alternative $a$ vs. $a / t$ plot by using entire kinetics

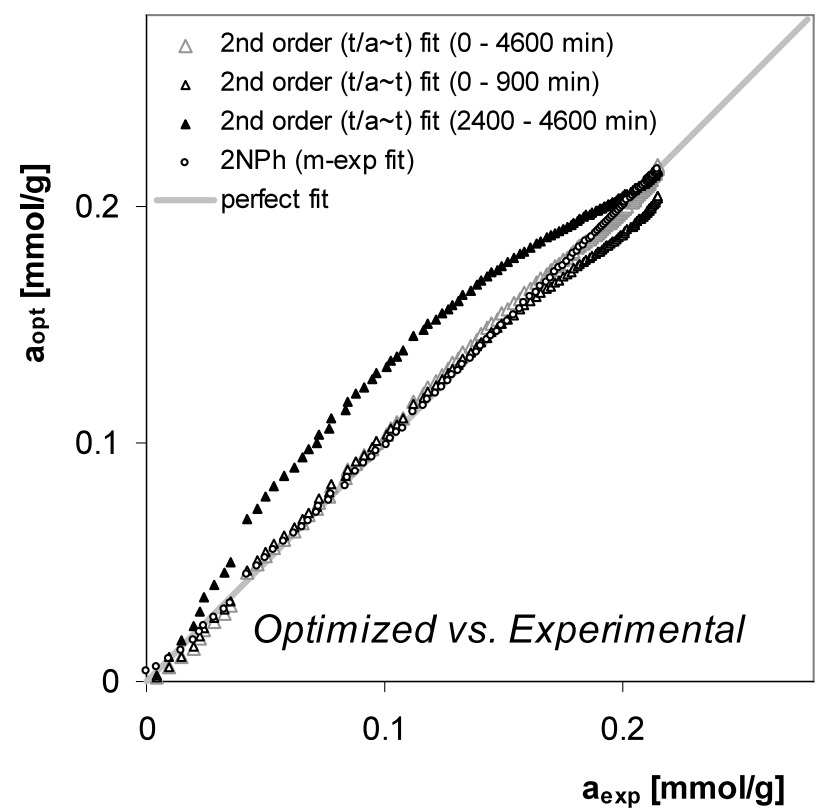

Fig. 10 Comparison of optimized and experimental points corresponding to the adsorption kinetics of 2-nitrophenol (left) and 2-chlorophenol (right) on RIAA carbon. Fitted results are obtained by using entire kinetic data (large triangle) and data sub-ranges for the initial

dation of carbon takes place; this process is exothermic as is revealed on the DTA curve with maximum at $554{ }^{\circ} \mathrm{C}$. At higher temperatures $640-950^{\circ} \mathrm{C}$ we can observe further pyrolysis process, which is visible as a wide exothermic peak on the DTA curve. This process is connected with oxygen diffusion into the micropore system (Skowroński 1979). Slight mass changes (about $1 \%$ ) in the range $200-400^{\circ} \mathrm{C}$ are connected with $\mathrm{CO}_{2}$ desorption.

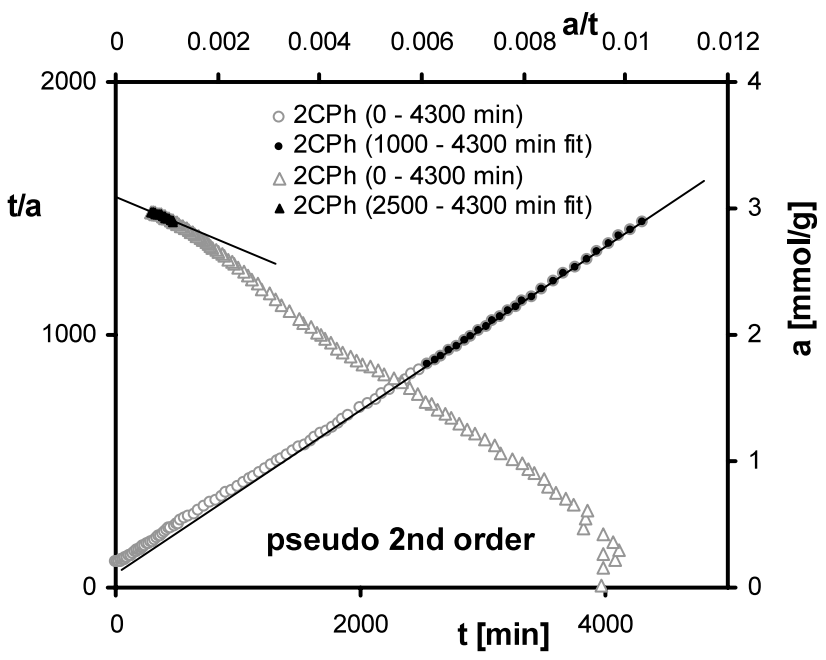

data in data close to the equilibrium (see Tables 5 and 6) $(4,5)$ (units as in Table 5)

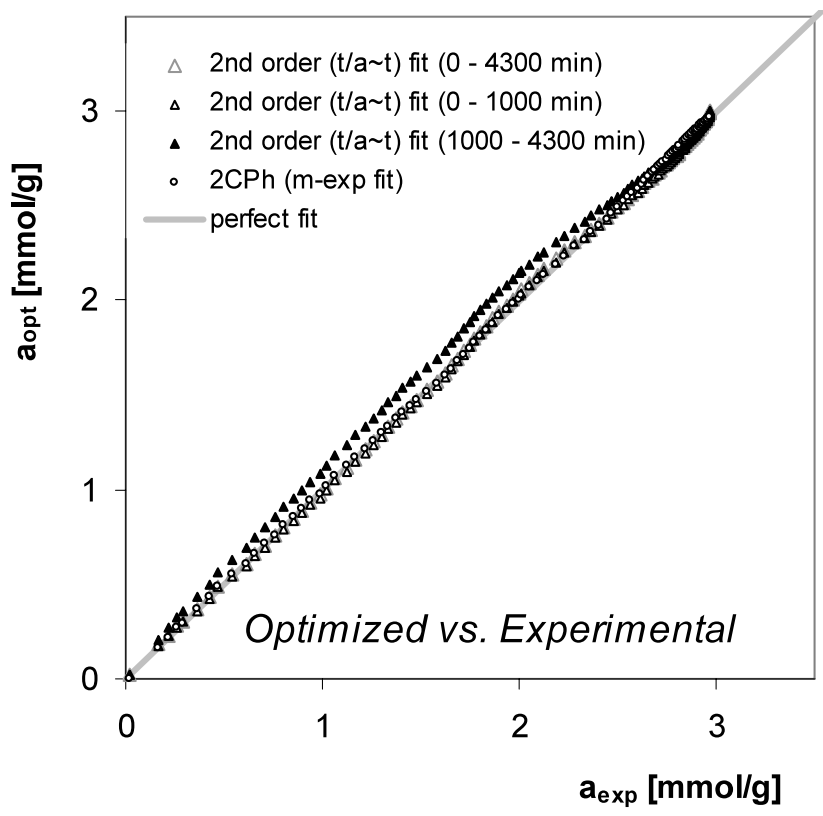

part of kinetics (white triangles) and close-to-equilibrium range (black triangles) (4). Thick gray lines correspond to the perfect fit, whereas open circles are calculated according to the m-exp fitting (Tables 4, 5 and 6) (6)

The processes of oxidation of carbonaceous materials depend strongly on their porosity and surface properties. Regarding the complex character of phenols interactions with carbon surface the processes of their thermal degradation are complicated and pass through many stages (Figs. 11, 12, 13 and 14 , curves b, c, d). At first up to $100^{\circ} \mathrm{C}$ we can observe on DTG and DTA curves the process of water removing (Amicarelli et al. 1980). In the temperature 


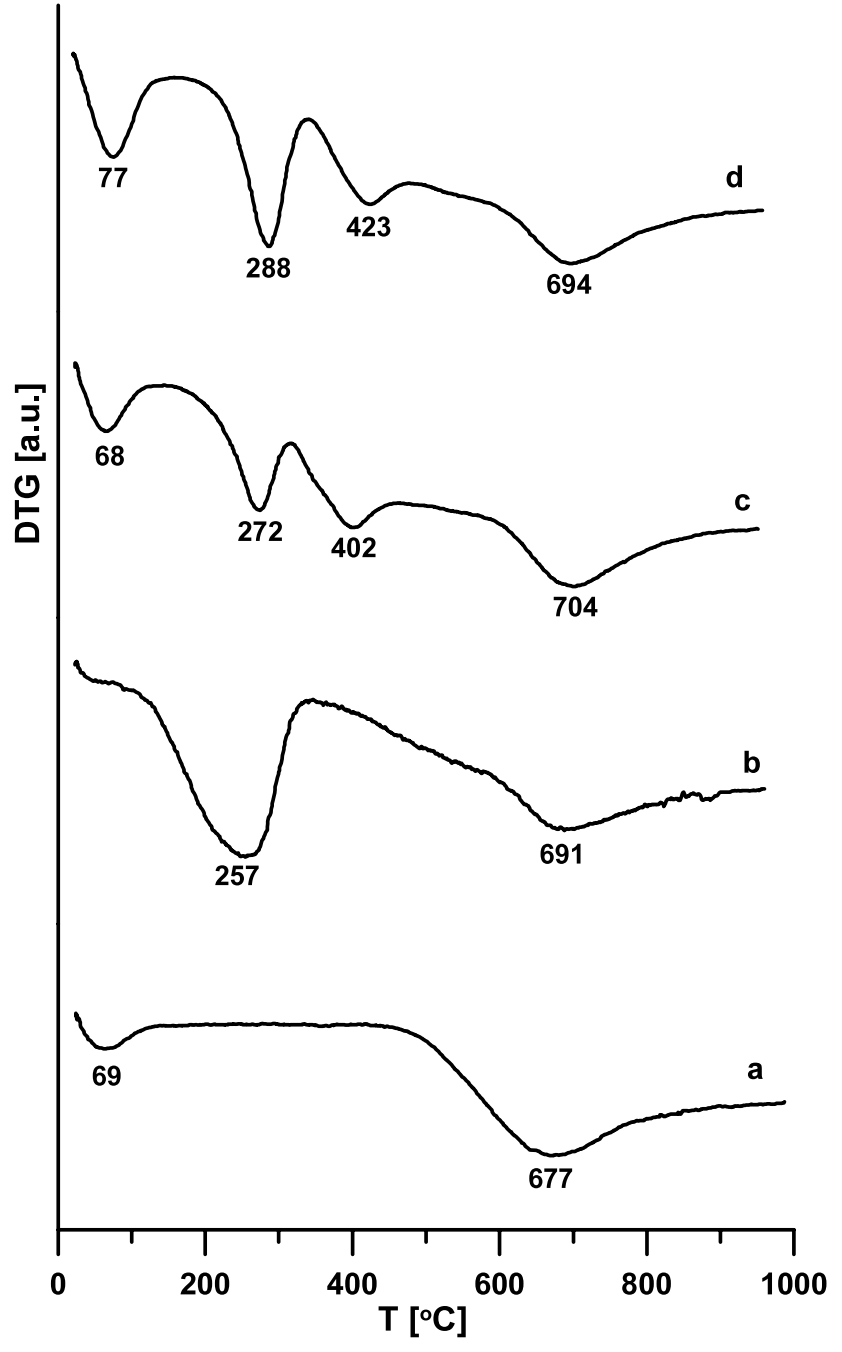

Fig. 11 Comparison of DTG curves measured for the pure carbon RIAA (a), carbon loaded with 2-nitrophenol (b), carbon loaded with 3-nitrophenol (c), and carbon loaded with 4-nitrophenol (d)

range $100-330^{\circ} \mathrm{C}$ thermodesorption of physically adsorbed phenols is detected. Further increase of temperature results in endothermic removing and decomposition of different forms of phenols (e.g., phenol, benzyl, furan, dimers) and carbon pyrolysis (Tóth et al. 2009; Moreno-Castilla et al. 1995b). The temperatures corresponding to these stages and the character of interactions of phenols with carbon strongly depend on the character of functional groups, but also on their positions with relation to the $\mathrm{OH}$ group. The DTG and DTA dependences presented in Figs. 11, 12, 13 and 14 for the carbon RIAA loaded with nitro- and chlorophenols show some differences. In the case of chlorophenol loaded samples (Figs. 13 and 14) a wide peaks on DTG curve at 100$400{ }^{\circ} \mathrm{C}$ with minima at 195,236 , and $220^{\circ} \mathrm{C}$ (for 2-, 3-, 4chlorophenol, respectively) evidence the physical character of adsorption process of these compounds on carbon. The similarity of thermogravimetric curves and mass losses in

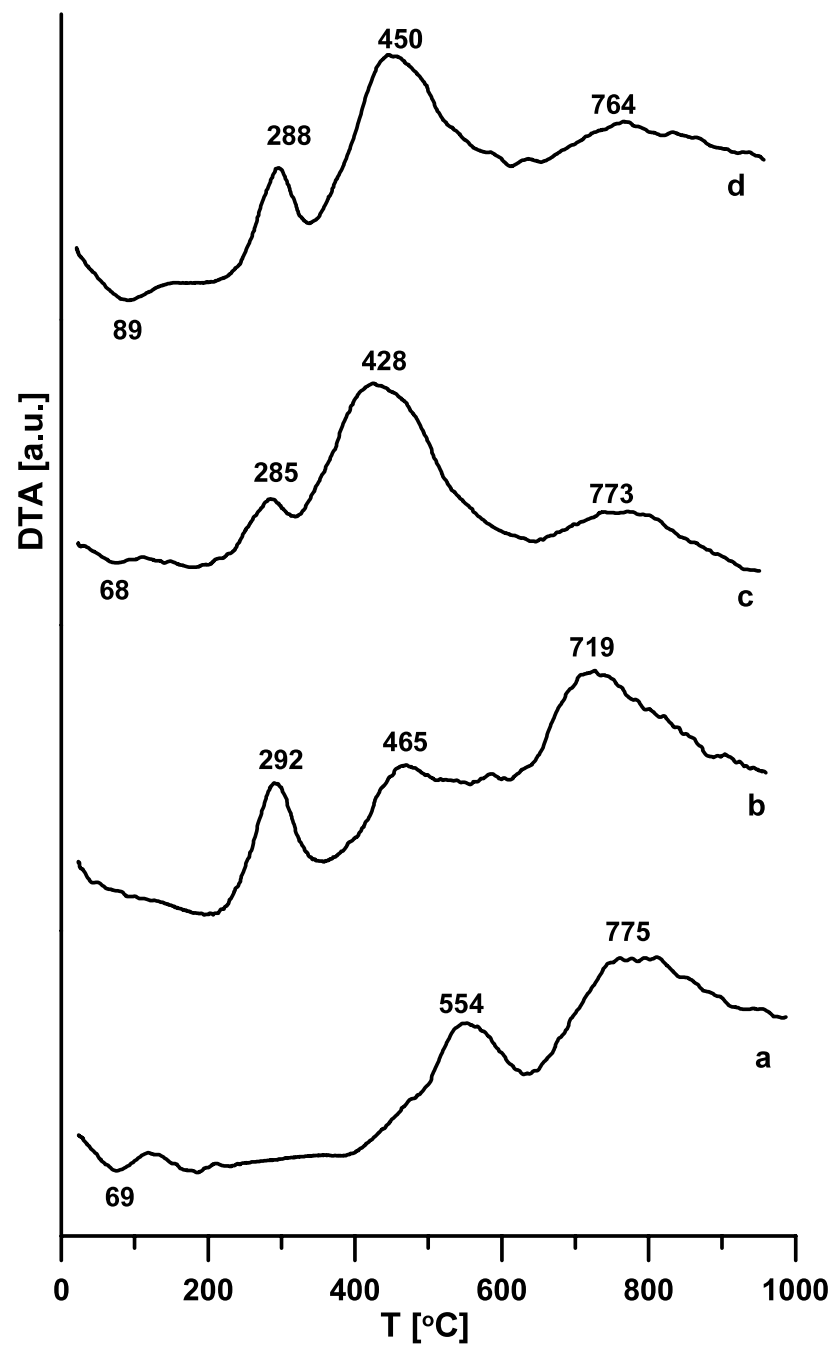

Fig. 12 Comparison of DTA curves measured for the pure carbon RIAA (a), carbon loaded with 2-nitrophenol (b), carbon loaded with 3-nitrophenol (c), and carbon loaded with 4-nitrophenol (d)

Table 7 Weight losses determined from TG curved for pure and solute loaded carbon RIAA

\begin{tabular}{llll}
\hline \multirow{2}{*}{ Samples } & \multicolumn{3}{l}{ Weight losses $(\%)$} \\
\cline { 2 - 4 } & $25-100{ }^{\circ} \mathrm{C}$ & $200-400{ }^{\circ} \mathrm{C}$ & $500-900{ }^{\circ} \mathrm{C}$ \\
\hline RIAA & 2 & 1 & 69 \\
$2-\mathrm{CPh}$ & 1 & 15 & 70 \\
$3-\mathrm{CPh}$ & 2 & 15 & 63 \\
$4-\mathrm{CPh}$ & 2 & 14 & 74 \\
$2-\mathrm{NPh}$ & 0 & 30 & 59 \\
$3-\mathrm{NPh}$ & 1 & 16 & 63 \\
$4-\mathrm{NPh}$ & 2 & 17 & 66 \\
\hline
\end{tabular}

different temperature ranges (Table 7) is a result of similarity of adsorption character and uptake for these derivatives. 


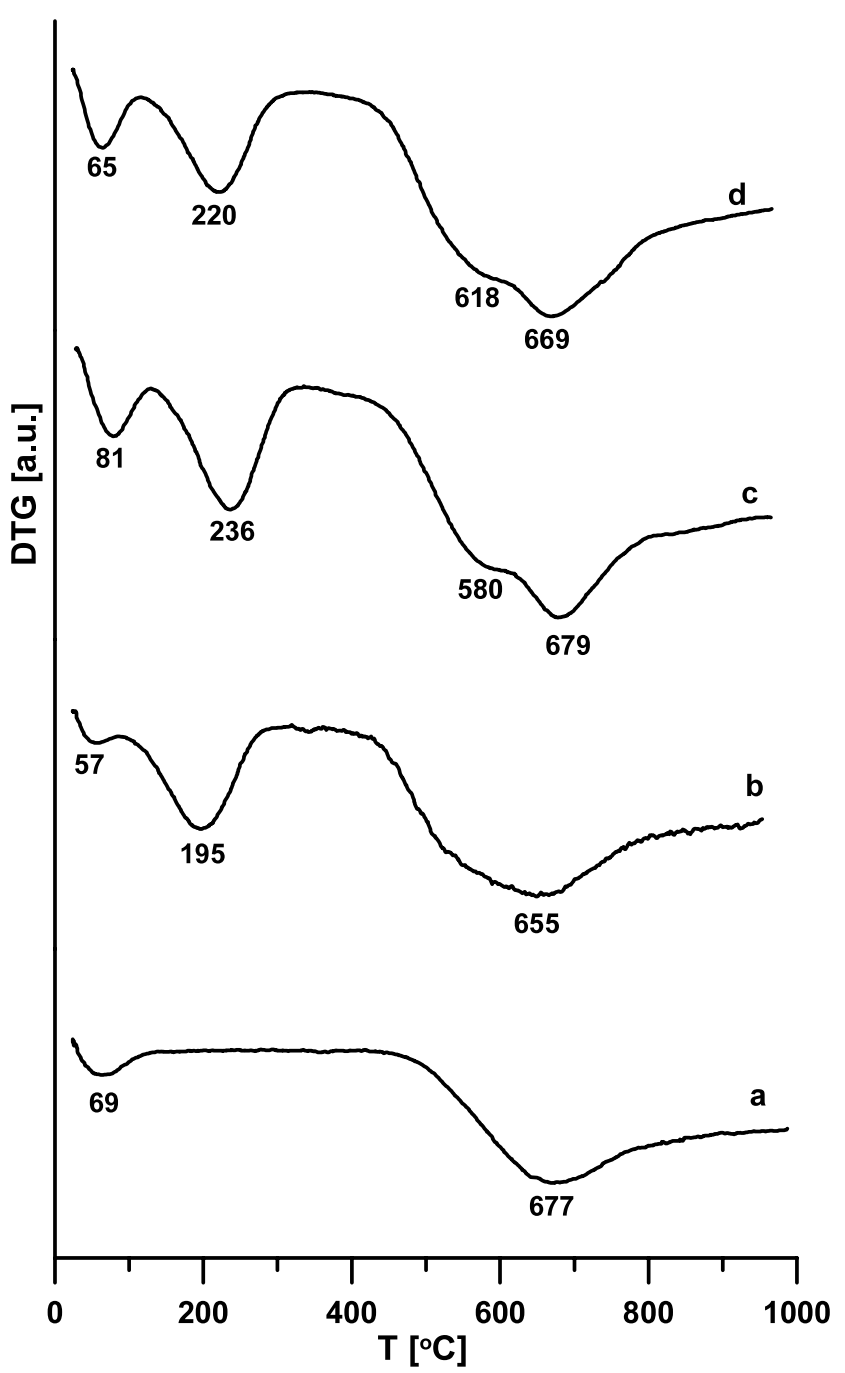

Fig. 13 Comparison of DTG curves measured for the pure carbon RIAA (a), carbon loaded with 2-chlorophenol (b), carbon loaded with 3-chlorophenol (c), and carbon loaded with 4-chlorophenol (d)

Adsorption of nitrophenols on carbon surface is a more complicated process. The TG, DTG and DTA curves are differentiated with regard to nitrophenol shapes and temperatures of decomposition. Above $100^{\circ} \mathrm{C}$ on DTG curves we can observe 3 exothermic peaks. The first one with minima at 257,272 , and $288^{\circ} \mathrm{C}$ (for 2-, 3-, 4-nitrophenol, respectively) is connected with the process of removing of physically adsorbed phenolic molecules. This peak is the most intensive and wide for the carbon sample loaded with 2-nitrophenol, and the temperature of thermodesorption is the lowest. It means that the interactions of 2-nitrophenol with carbon RIAA are weaker in comparison to the other two derivatives and that this compound is adsorbed mainly physically (its functional groups form intramolecular hydrogen bonding). On the other hand, this effect seems in contradiction to the stronger adsorption effects in aqueous solution, however, this apparent ambiguity may be explained

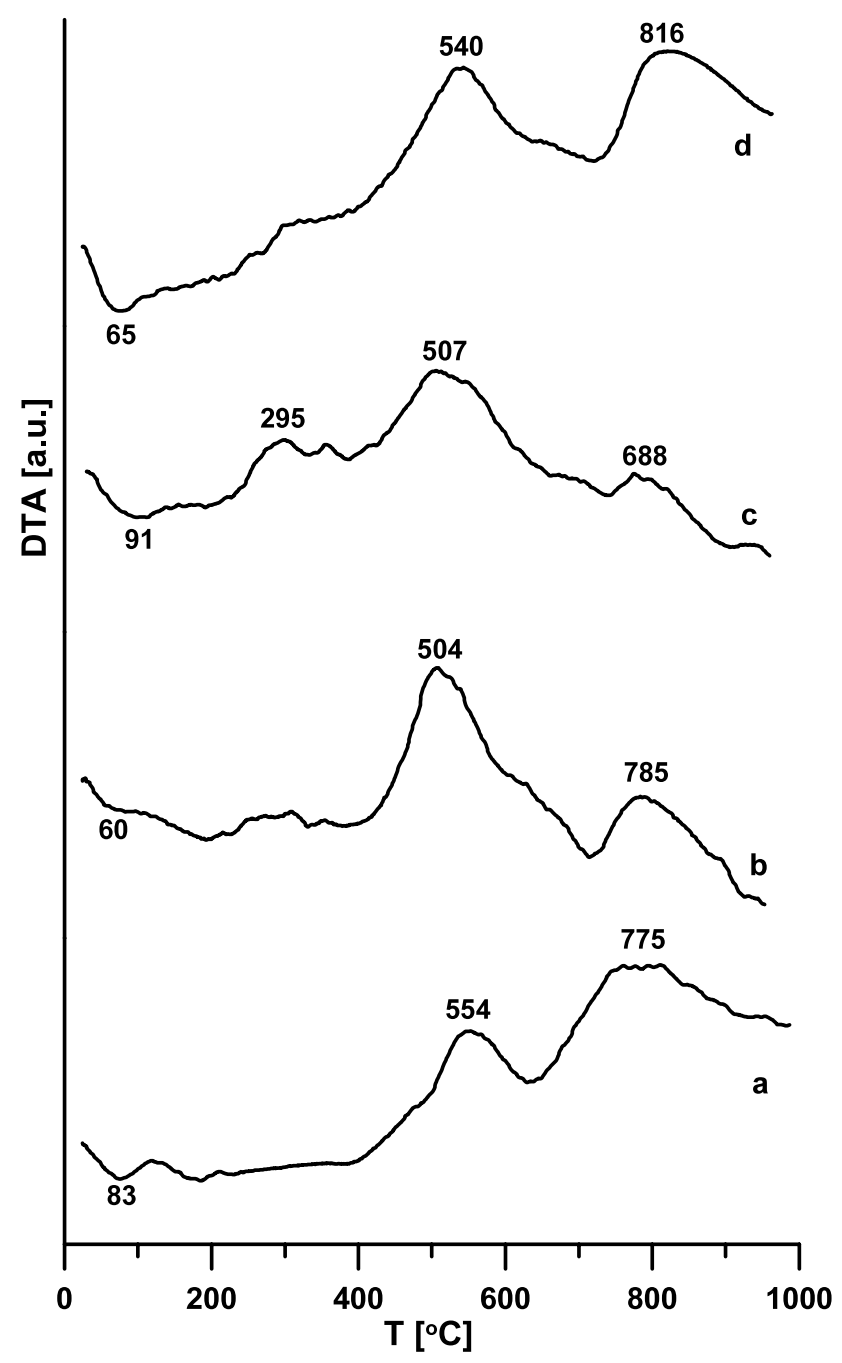

Fig. 14 Comparison of DTA curves measured for the pure carbon RIAA (a), carbon loaded with 2-chlorophenol (b), carbon loaded with 3-chlorophenol (c), and carbon loaded with 4-chlorophenol (d)

as the result of its weak solvation and lower solubility rather than stronger adsorption forces. The peaks on DTG curves with minima at 402 and $423^{\circ} \mathrm{C}$ for the carbon samples loaded with 3- and 4-nitrophenol indicate the contribution of chemisorption in adsorption process. These results evidence the effect of position of substituent group on interactions with adsorbent surface. Adsorption of nitrophenols on carbon results in decrease of thermal stability or surface complexes and is accompanied by the shift of DTA peaks corresponding to thermooxidation process towards lower temperatures.

\section{Conclusion}

Adsorption of all studied chlorophenols was comparable as a result of slight differences among their solubilities. For 
nitrophenols a distinctly higher adsorption of 2-nitrophenol was observed indicating the stronger hydrophobic interactions of this less soluble derivative with carbon surface. In the case of nitrophenols the decrease of adsorption with temperature increase was observed as a result of increase of solubility and oscillation energy of adsorbate molecules. The temperature effect was stronger for 2-nitrophenol. For chlorophenols the temperature effect was slight as a result of superposition of various opposite effects; the larger influence was observed for 2-chlorophenol.

The similarities of kinetic curves for 3- and 4-nitro- and chlorophenols were found. The kinetics for 2-nitro- and chlorophenol is a little different in comparison to the other two derivatives. The second order equation used in the "standard" linear form $t / a$ vs. $t$ for fitting to the experimental kinetic data occurred to be very good, only at the region close to equilibrium slight deviations from experimental points were observed. In the case of the alternative linear PSOE plot $a$ vs. $a / t$ the deviations from linearity was quite distinct, especially in the region near equilibrium. The parameters obtained by fitting PSOE in the "standard" linear form indicate reliable estimation of the equilibrium adsorption values, however, for the values of rate coefficient strong deviations were obtained. The multi-exponential equation describes the kinetics curves very well for all studied experimental systems.

Analysis of the DTG and DTA curves measured for the pure carbon RIAA, and the carbon loaded with adsorbates allowed to study the complex character of phenols interactions with carbon surface dependent on the character of functional groups. The DTG and DTA dependences for the carbon RIAA loaded with chlorophenols show high similarity and evidence the physical character of their adsorption on carbon. In the case of carbon samples loaded with nitrophenols the TG, DTG and DTA curves are differentiated with regard to shape and temperatures of decomposition. The exothermic peaks on DTG curves located above $100{ }^{\circ} \mathrm{C}$ connected with the process of removing of physically adsorbed solute are different for 2-, 3- and 4-nitrophenol. For 2-nitrophenol loaded carbon, the weakest intensity and width of this peak, and the lowest thermodesorption temperature confirm weaker interactions of this adsorbate with carbon and the physical mechanism of its adsorption. For the carbon samples loaded with 3- and 4-nitrophenol certain share of chemisorption was found.

Open Access This article is distributed under the terms of the Creative Commons Attribution Noncommercial License which permits any noncommercial use, distribution, and reproduction in any medium, provided the original author(s) and source are credited.

\section{References}

Amicarelli, V., Baldassare, G., Liberti, L.: Investigation of lowtemperature regeneration of activated carbon. J. Therm. Anal. 18, $155-160$ (1980)

Azizian, S.: Kinetic models of sorption: a theoretical analysis. J. Colloid Interface Sci. 276, 47-52 (2004)

Brandt, A., Bülow, M., Derylo-Marczewska, A., Goworek, J., Schmeißer, J., Schöps, W., Unger, B.: Novel zeolite composites and consequences for rapid sorption processes. Adsorption 13(34), 267-279 (2007)

Cheung, C.W., Porter, J.F., McKay, G.: Water Res. 35, 605-612 (2001)

Crank, J.: Mathematics of Diffusion. Clarendon, Oxford (1975)

Deryło-Marczewska, A., Jaroniec, M.: Adsorption of organic solutes from dilute solutions on solids. In: Matijević, E. (ed.) Surface and Colloid Science, vol. 14, pp. 301-379. Plenum, New York (1987)

Deryło-Marczewska, A., Marczewski, A.W.: Influence of pH and adsorbate structure on adsorption of benzene derivatives on activated carbon. In: Do, D.D. (ed.) Adsorption Science and Technology, pp. 174-178. World Scientific, Singapore (2000)

Deryło-Marczewska, A., Marczewski, A.W.: Effect of adsorbate structure on adsorption from solutions. Appl. Surf. Sci. 196, 264-272 (2002)

Deryło-Marczewska, A., Swiatkowski, A., Buczek, B., Biniak, S.: Adsorption equilibria in the systems: aqueous solutions of organics-oxidized activated carbon samples obtained from different parts of granules. Fuel 85(3), 410-417 (2006)

Deryło-Marczewska, A., Marczewski, A.W., Winter, Sz., Sternik, D.: Studies of adsorption equilibria and kinetics in the systems: aqueous solution of dyes-mesoporous carbons. Appl. Surf. Sci. 256, 1164-1170 (2010)

Franz, M., Arafat, H.A., Pinto, N.G.: Effect of chemical surface heterogeneity on the adsorption mechanism of dissolved aromatics on activated carbon. Carbon 38, 1807-1819 (2000)

Gregg, S.J., Sing, K.S.W.: Adsorption, Surface Area and Porosity. Academic Press, London (1982)

Haydar, S., Ferro-Garcia, M.A., Rivera-Utrilla, J., Joly, J.P.: Adsorption of p-nitrophenol on activated carbon with different oxidations. Carbon 41, 387-395 (2003)

Ho, Y.S., McKay, G.: Sorption of dye from aqueous solution by peat. Chem. Eng. J. 70(2), 115-124 (1998a)

Ho, Y.S., McKay, G.: Kinetic models for the sorption of dye from aqueous solution by wood. Process Saf. Environ. Prot. B 76(2), 183-191 (1998b)

Ho, Y.S.: Second-order kinetic model for the sorption of cadmium onto tree fern: a comparison of linear and non-linear methods. Water Res. 40, 119-125 (2006a)

Ho, Y.S.: Review of second-order models for adsorption systems. J. Hazard. Mater. B 136, 681-689 (2006b)

Horvath, G., Kawazoe, K.: Method for the calculation of effective pore size distribution in molecular sieve carbon. J. Chem. Eng. Jpn. 16, 470-475 (1983)

Hsieh, Ch.-T., Teng, H.: Influence of mesopore volume and adsorbate size on adsorption capacities of activated carbons in aqueous solutions. Carbon 38, 863-869 (2000)

Jaroniec, M., Madey, R.: Physical Adsorption on Heterogeneous Solids. Elsevier, Amsterdam (1988)

Kruk, M., Jaroniec, M., Gadkaree, K.P.: Nitrogen adsorption studies of novel synthetic active carbons. J. Colloid Interface Sci. 192, 250-256 (1997)

Lagergren, S.: Zur theorie der sogenannten adsorption gelöster stoffe. Kung. Svenska Vettenskapsakad. Handl. 24(4), 1-39 (1898)

László, K.: Adsorption from aqueous phenol and aniline solutions on activated carbons with different surface chemistry. Colloids Surf. A, Physicochem. Eng. Asp. 265, 32-39 (2005) 
Leng, C.-C., Pinto, N.G.: Effects of surface properties of activated carbons on adsorption behaviour of selected aromatics. Carbon 35(9), 1375-1385 (1997)

Li, L., Quinlivan, P.A., Knappe, D.R.U.: Effects of activated carbon surface chemistry and pore structure on the adsorption of organic contaminants from aqueous solution. Carbon 40, 2085$2100(2002)$

Lillo-Ródenas, M.A., Cazorla-Amorós, D., Linares-Solano, A.: Behaviour of activated carbons with different pore size distributions and surface oxygen groups for benzene and toluene adsorption at low concentrations. Carbon 43, 1758-1767 (2005)

Liu, Y., Shen, L.: From Langmuir kinetics to first- and second-order rate equations for adsorption. Langmuir 24, 11625-11630 (2008)

Marczewski, A.W.: Kinetics and equilibrium of adsorption of organic solutes on mesoporous carbons. Appl. Surf. Sci. 253, 5818-5826 (2007)

Marczewski, A.W.: Kinetics and equilibrium of adsorption of dissociating solutes from aqueous solutions on mesoporous carbons. Pol. J. Chem. 82, 271-281 (2008)

Marczewski, A.W.: Application of mixed order rate equations to adsorption of methylene blue on mesoporous carbons. Appl. Surf. Sci. 256, 5145-5152 (2010)

Moreno-Castilla, C.: Adsorption of organic molecules from aqueous solutions on carbon materials. Carbon 42, 83-94 (2004)

Moreno-Castilla, C., Rivera-Utrilla, J., Lopez-Ramon, M.V., CarrascoMarin, F.: Adsorption of some substituted phenols on activated carbons from a bituminous coal. Carbon 33(6), 845-851 (1995a)

Moreno-Castilla, C., Rivera-Utrilla, J., Joly, J.P., Lopez-Ramon, M.V., Ferro-Garcia, M.A., Carrasco-Marin, F.: Thermal regeneration of an activated carbon exhausted with different substituted phenols. Carbon 33(10), 1417-1423 (1995b)
Okolo, B., Park, C., Keane, M.A.: Interaction of phenol and chlorophenols with activated carbon and synthetic zeolites in aqueous media. J. Colloid Interface Sci. 226, 308-317 (2000)

Płaziński, W., Rudziński, W., Płazińska, A.: Theoretical models of sorption kinetics including a surface reaction mechanism: a review. Adv. Colloid Interface Sci. 152, 2-13 (2009)

Radovic, L.R., Silva, I.F., Ume, J.I., Menéndez, J.A., Leon y Leon, C.A., Scaroni, A.W.: An experimental and theoretical study of the adsorption of aromatics possessing electron-withdrawing and electro-donating functional groups by chemically modified activated carbons. Carbon 35, 1339-1348 (1997)

Radovic, L.R., Moreno-Castilla, C., Rivera-Utrilla, J.: Carbon materials as adsorbents in aqueous solutions. In: Radovic, L.R. (ed.) Chemistry and Physics of Carbon, vol. 27, pp. 227-405. Dekker, New York (2001)

Ravikovitch, P.I., Vishnyakov, A., Russo, R., Neimark, A.V.: Unified approach to pore size characterization of microporous carbonaceous materials from $\mathrm{N}_{2}, \mathrm{Ar}$, and $\mathrm{CO}_{2}$ adsorption isotherms. Langmuir 16, 2311-2320 (2000)

Rudziński, W., Płaziński, W.: Theoretical description of the kinetics of solute adsorption at heterogeneous solid/solution interfaces. On the possibility of distinguishing between the diffusional and the surface reaction kinetics models. Appl. Surf. Sci. 253, 5827-5840 (2007)

Skowroński, J.M.: Thermal investigation of active carbons in presence of air. J. Therm. Anal. 16, 463-469 (1979)

Tóth, A., Nóvak, C., László, K.: The effect of ionic environment on the TG response of phenol loaded PET-based porous carbons. J. Therm. Anal. Calorim. 97, 273-280 (2009)

Weber, W.J., Morris, J.C.: Kinetics of adsorption on carbon from solution. J. Sanit. Eng. Div. ASCE 89(SA2), 31-59 (1963) 